\title{
Regulation of cancer stem cells in triple negative breast cancer
}

\author{
Norman Fultang', Madhuparna Chakraborty², Bela Peethambaran² \\ 'Department of Pathology and Laboratory Medicine, University of Pennsylvania, Philadelphia, PA 19140, USA. \\ ${ }^{2}$ Department of Biological Sciences, The University of the Sciences, Philadelphia, PA 19140, USA.
}

Correspondence to: Dr. Bela Peethambaran, Department of Biological Sciences, The University of the Sciences, 600 S 34 rd St, Philadelphia, PA 19104, USA. E-mail: b.peethambaran@usciences.edu

How to cite this article: Fultang N, Chakraborty M, Peethambaran B. Regulation of cancer stem cells in triple negative breast cancer. Cancer Drug Resist 2021;4:321-42. http://dx.doi.org/10.20517/cdr.2020.106

Received: 24 Nov 2020 First Decision: 23 Dec 2020 Revised: 28 Dec 2020 Accepted: 6 Jan 2021 Available online: 19 Jun 2021

Academic Editor: Godefridus J. Peters Copy Editor: Yue-Yue Zhang Production Editor: Jing Yu

\begin{abstract}
Triple Negative Breast Cancer (TNBC) is the most lethal subtype of breast cancer. Despite the successes of emerging targeted therapies, relapse, recurrence, and therapy failure rates in TNBC significantly outpace other subtypes of breast cancer. Mounting evidence suggests accumulation of therapy resistant Cancer Stem Cell (CSC) populations within TNBCs contributes to poor clinical outcomes. These CSCS are enriched in TNBC compared to non-TNBC breast cancers. The mechanisms underlying CSC accumulation have been well-characterized and discussed in other reviews. In this review, we focus on TNBC-specific mechanisms that allow the expansion and activity of self-renewing CSCs. We highlight cellular signaling pathways and transcription factors, specifically enriched in TNBC over non-TNBC breast cancer, contributing to stemness. We also analyze publicly available singlecell RNA-seq data from basal breast cancer tumors to highlight the potential of emerging bioinformatic approaches in identifying novel drivers of stemness in TNBC and other cancers.
\end{abstract}

Keywords: Cancer stem cells, TNBC, transcriptional regulation, breast cancer

\section{INTRODUCTION}

Breast cancer remains the most commonly diagnosed cancer in women and the second leading cause of cancer-related deaths in women worldwide ${ }^{[1]}$. Breast cancer represents a highly heterogeneous group of neoplasms encompassing varied cell phenotypes with significant clinical implications. To

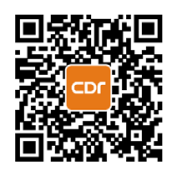


aid characterization and guide therapeutic decisions, breast cancer has been stratified into several morphologically and molecularly distinct subtypes. These include Luminal A/B, Human Epidermal Growth Factor (HER2)-enriched, and Triple Negative (TNBC) subtypes ${ }^{[2]}$. TNBC is the most aggressive subtype of breast cancer and is characterized by hyperproliferative cells lacking expression of hormone receptors (estrogen and progesterone) and HER $2^{[3,4]}$. Therapeutic avenues for TNBC are often limited due to the absence of these receptors and mortality rates far exceed other subtypes ${ }^{[3,5-7]}$. Additionally, TNBCs respond less to conventional chemotherapy and patients are at increased risk of recurrence and relapse ${ }^{[5,7]}$. Overall survival also lags far behind other non-TNBC subtypes predominantly due to therapy failure and/or relapse ${ }^{[1,3,5,7]}$. Accumulating evidence now suggests that TNBCs are enriched in therapy resistant Cancer Stem Cells (CSC), compared to non-TNBC subtypes, which significantly contribute to heightened mortality, therapy failure, and recurrence ${ }^{[8-10]}$.

CSCs are a small population of self-renewing tumor cells that persist after therapy and differentiate into all the cell types within the original tumor, reprising its heterogeneity ${ }^{[11,12]}$. Originally identified as selfrenewing cells in leukemia with a $\mathrm{CD} 34^{+} \mathrm{CD} 38$ phenotype, they have since been identified in several solid and hematologic malignancies, including breast cancer, as both hyperproliferative and slow-cycling cells with a consensus $\mathrm{CD} 44^{+} \mathrm{CD} 24^{-} / \mathrm{ALDH}^{+}{ }^{+}$phenotype ${ }^{[11]}$. These tumor-initiating CSCs are especially adept at repopulating tumors in animal disease models compared to non-CSC tumor cells ${ }^{[12]}$.

During embryonic development and throughout life, highly plastic stem cells differentiate into various cell and tissue types in processes spatiotemporally regulated by developmental pathways such as the wingless signaling pathway (Wnt)/ $\beta$-catenin, Notch (neurogenic locus notch homolog protein 1 ), and Sonic Hedgehog pathways ${ }^{[11,13-15]}$. During carcinogenesis, aberrant regulation of these pathways allows cancer cells to acquire a "stem-cell"-like phenotype with increased ability to proliferate, tolerate hostile environments, and differentiate into different cell types ${ }^{[13,14,16]}$. This stem-cell oncogenic conversion is also mediated by factors within the tumor microenvironment (TME) and deregulated epigenetic and transcriptional $\operatorname{programs}^{[16-18]}$.

In TNBC, deregulation of stemness pathways is even more pronounced than in non-TNBC breast cancers, conferring TNBC CSCs (TNBCSCs) an especially problematic clinical phenotype ${ }^{[8-10]}$. Indeed, several analyses of human breast carcinomas have revealed TNBCs harbor the highest percentage of $\mathrm{CD} 44^{+} \mathrm{CD} 24{ }^{-} \mathrm{ALDH} 1{ }^{+} \mathrm{CSCs}$, a feature that usually correlates negatively with chemotherapy response, disease-free survival, metastasis-free survival, and overall survival ${ }^{[19]}$. In TNBC patients, chemotherapy and radiotherapy eradicate most hyperproliferative cells within the TME but fail to kill quiescent, slow-cycling TNBCSCs, allowing them to reinitiate the tumor (source). TNBCSCs are resistant to a host of therapeutic agents-a phenomenon referred to as Multi-Drug Resistance (MDR $)^{[20-22]}$. The mechanisms of MDR, as well as new therapeutic approaches being pursued in both CSCs and TNBCSCs, have been reviewed extensively in previous publications ${ }^{[2,23]}$. This review focuses on cellular pathways and epigenetic and transcriptional factors that regulate stemness in TNBC. We also perform an analysis on publicly available TNBC single-cell RNA sequencing [single cell ribonucleic acid sequenceing (scRNA-seq)] data to highlight the potential of emerging systems biology approaches in identifying novel drivers of stemness in TNBC and other cancers.

\section{CELLULAR PATHWAYS REGULATING STEMNESS IN TNBC}

Compared to other subtypes of breast cancer, TNBC cells are enriched in several stemness pathways. These include classical stem-cell pathways such as Wnt/ $\beta$-catenin (beta), Notch, and Hh, which regulate cell fate and tissue patterning in early life, as well as cZEBell proliferation axes such as JAK/signal transducer and activator of transcription 3 (STAT3) $/ 5^{[11,13-15,24]}$. Regulators of Epithelial-to-Mesenchymal Transition (EMT), an essential developmental process during organogenesis, including SNAIL, and twist family bHLH 


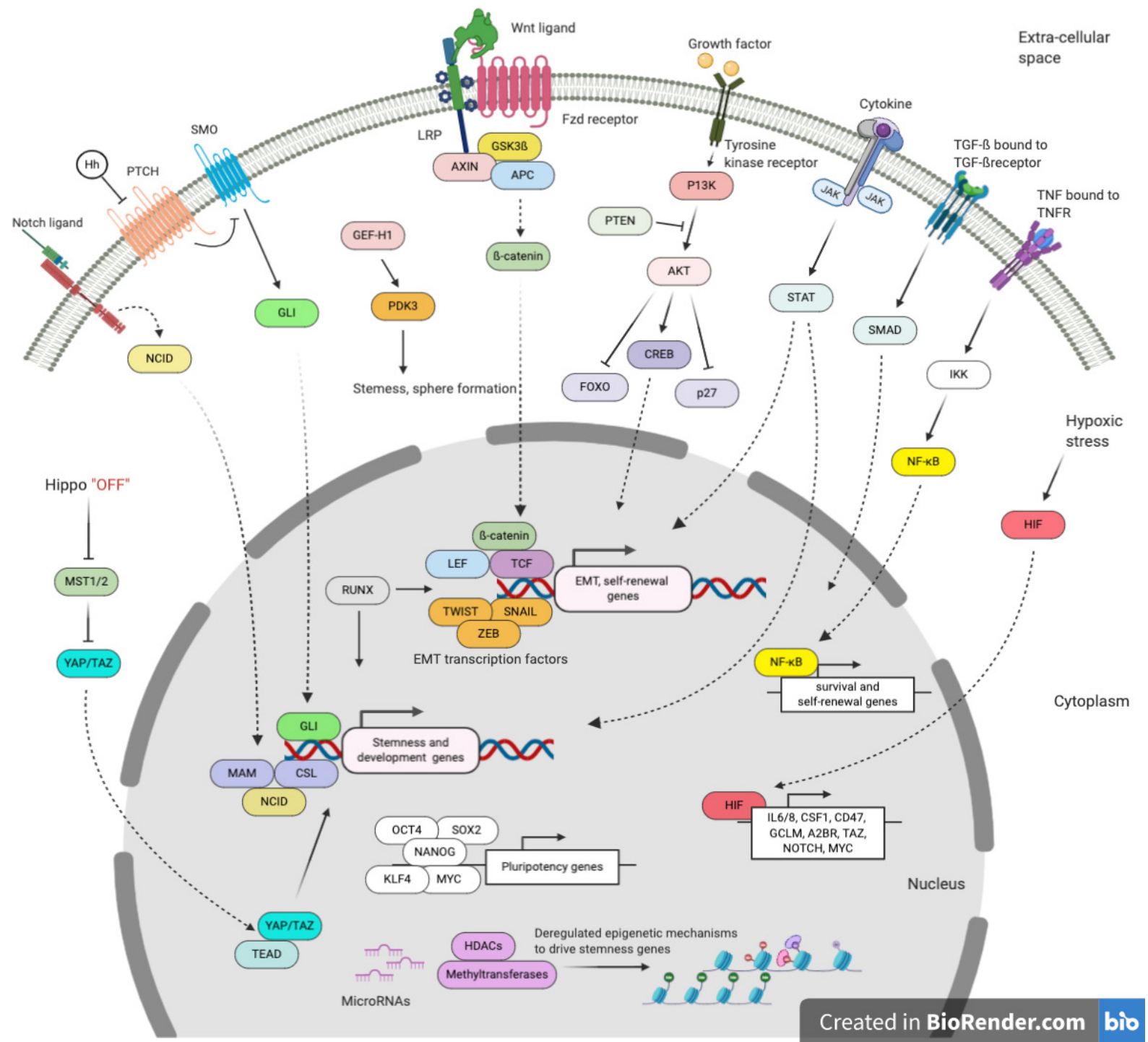

Figure 1. Signaling pathways and epigenetic and transcriptional mechanisms deregulated in TNBC contributing to stemness. Created using Biorender.com

transcription factor 1 (TWIST) transcription factors, are also vital to TNBC stemness ${ }^{[25-27]}$. Recent evidence also suggests TME hypoxia and increased activity of pluripotency mediators such as OCT4, SOX2, and master regulator of cell cycle entry and proliferative metabolism (MYC), in TNBC compared to nonTNBC breast cancer, contribute to the elevated stemness phenotype ${ }^{[28-30]}$. These and several other molecular regulators of TNBC stemness are evaluated in this section [Figure 1].

\section{Wnt/ $\beta$-catenin}

The non-canonical and canonical Wnt signaling pathways are highly conserved developmental pathways governing cell polarity and tissue patterning in early life ${ }^{[13]}$. Canonical Wnt signaling is initiated by binding of Wnt ligands to either frizzled domain (FZD) or low-density-lipoprotein (LRP) family receptors resulting in the formation of a Wnt complex. This complex recruits and occupies members of the $\beta$-catenin destruction complex, preventing proteasomal degradation of $\beta$-catenin. Stabilized $\beta$-catenin then translocates to the nucleus where it acts as a transcriptional coactivator in combination with $\mathrm{T}$-cell factor (TCF) and lymphoid enhancer-binding factor (LEF) ${ }^{[13]}$. Non-canonical Wnt signaling is also initiated by 
Wnt ligand binding but does not culminate in $\beta$-catenin stabilization. Both pathways result in increased proliferation, loss of E-cadherin/EMT, mammosphere formation, invasiveness, and colony formation ${ }^{[13,17,31]}$.

Aberrant activation of Wnt signaling is a hallmark of several cancers including breast cancer ${ }^{[13,14,31,32]}$. Compared to non-TNBC breast cancer, TNBC is enriched in a number of Wnt pathway genes ${ }^{[32-34]}$. Aberrant Wnt signaling has been linked with increased stemness and chemoresistance in TNBC and TNBCSCs. Xu et al. ${ }^{[35]}$ showed highly active Wnt-signaling is required for TNBC tumorigenesis, migration, stemness, anchorage-independent growth, and chemoresistance. In a 4T1-mouse model of TNBC, Jang et al. ${ }^{[36]}$ showed Wnt-signaling is enriched in TNBCSCs compared to the bulk tumor population. Activation of Wnt-signaling via WNT3A treatment significantly increased the number of ALDH+ TNBCSCs, while inhibition of Wnt-signaling had the opposite effect.

Wnt signaling was also shown to promote CSC cycling via transcription of cell cycle regulators Cyclin $\mathrm{D} 1$ and $\mathrm{MYC}^{[37]}$. Wnt signaling also contributes to dedifferentiation of breast cancer cells into pluripotent $\mathrm{CSCs}^{[38,39]}$; Wnt co-receptor LRP8 was similarly shown to promote TNBCSCs via conversion into a basalmesenchymal stem-cell-like phenotype ${ }^{[40]}$. Non-canonical Wnt receptors including receptor tyrosine kinase like orphan receptor 1 (ROR1) and receptor tyrosine kinase like orphan receptor 2 (ROR2), which are especially enriched in ER negative breast cancer ${ }^{[33,41]}$, have been shown to promote stemness in ER negative breast cancer via interactions with Yes associated Protein 1 (YAP)/WW domain-containing transcription regulator protein 1 (TAZ) and BMI-1 stemness pathways ${ }^{[42]}$. Additionally, several non-Wnt molecules, including Enhancer of zeste homolog 2 (EZH2), telomerase reverse transcriptase (TERT), Capillary morphogenesis gene 2 (CMG2), Histone-lysine N-methyltransferase (SMYD3), CD138, and Focal adhesion kinase (FAK), regulate CSCs in TNBC and other cancers via their interaction with Wnt effectors such as $\beta$-catenin and $\operatorname{LRP}^{\left[{ }^{[3-48]}\right.}$. Finally, Cleary et al. ${ }^{[49]}$ also demonstrated that a persistent population of tumorinitiating cells could reactivate Wnt-signaling following Wnt inhibition, repopulating the tumor and contributing to relapse. This finding underlines a core issue with targeting Wnt clinically-Wnt inhibitors usually abrogate Wnt signaling in tumor cells but not in CSCs, which persist and can rescue the hyperactive Wnt phenotype ${ }^{[49]}$. It is imperative that emerging therapeutic approaches target Wnt in CSCs. Altogether, the data from these studies suggest a vital role for Wnt signaling in TNBCSCs and TNBC recurrence.

\section{Notch signaling}

Notch signaling is a highly conserved developmental pathway that is triggered when Notch ligands (Deltalike-1/3/4, Jagged1, and Jagged2) bind to one of several Notch receptors (NOTCH1-4) on neighboring cells, triggering the latter's proteolytic cleavage and nuclear translocation ${ }^{[50-52]}$. In the nucleus, cleaved NOTCH binds transcription factors CBF-1/RBP-jк, Su(H), Lag-1 (CSL) and Mastermind (MAM) to form a ternary NICD (notch intracellular domain)/CSL transcription complex that regulates the expression of target genes $^{[50,51]}$.

Notch is aberrantly expressed in breast cancer CSCs where it promotes self-renewal and metastasis ${ }^{[3,54]}$. Notch is more significantly deregulated in TNBC compared to non-TNBC breast cancer-in fact, Notch ligands have been suggested as clinical markers for $\mathrm{TNBC}^{[52,55]}$. Increased Notch signaling in TNBCSCs might be mediated by transcription factor KLF4 and growth factor BMP4 Yu et al ${ }^{[56]}$ and Choi et al. ${ }^{[57]}$ demonstrated that KLF4 and BMP4 increased Notch1 and Jagged 1 expression in TNBCSCs, promoting cell motility and invasiveness. In another study, hypoxia, a hallmark of TNBC ${ }^{[58]}$, induced Jagged 1 expression in TNBCSCs, promoting metastasis and self-renewal ${ }^{[59]}$. Cell polarity regulator NUMB, which negatively regulates Notch-signaling, was also recently shown to be downregulated in TNBC, contributing to increased EMT and stemness ${ }^{[60]}$. Furthermore, loss of F-box and WD repeat domain-containing protein 7 (Fwb7), a tumor suppressor significantly reduced in $\mathrm{TNBC}^{[61]}$, increases Notch activity in breast cancer ${ }^{[62]}$. Liubomirski et al ${ }^{[63]}$ also recently highlighted a significant role for tumor-stroma interactions in promoting 
Notch activity in TNBC. Altogether, these studies highlight how Notch signaling is intricately regulated in TNBC to promote stemness and invasiveness.

\section{Hh signaling}

Similar to Wnt and Notch, Hh signaling is an important developmental pathway co-opted by tumors to promote stemness and tumor persistence ${ }^{[64,65]}$. Hh signaling consists of Hh ligands binding to transmembrane receptor Protein patched homolog $1(\mathrm{PTCH})$, regulating transmembrane protein smoothened (SMO), which induces downstream activation or repression of transcription via gliomaassociated oncogene (GLI) proteins. SMO positively regulates Hh signaling while PTCH negatively regulates SMO. In the absence of Hh ligands, $\mathrm{PTCH}$ binds and inhibits SMO. In the presence of $\mathrm{Hh}$ ligands bound to PTCH's extracellular domain, the latter undergoes a conformational change, preventing it from inhibiting SMO. SMO then induces downstream activation of GLI transcriptional regulators ${ }^{[65,66]}$. Individual GLI proteins, including Gli 1-3, have varying effects on the transcription of Hh target genes: GLI1 is a transcriptional activator, GLI3 a transcriptional repressor, and GLI2 a dual context-dependent regulator ${ }^{[64,65]}$.

Normally, Hh signaling regulates morphogenesis in early life and proliferation in adult stem cells ${ }^{[15]}$. In TNBC, Hh signaling has been associated with highly proliferative high-grade disease, increased metastases, and worse disease-free survival ${ }^{[67-69]}$. Several transcriptional targets of Hh signaling in TNBC, including $\mathrm{ABCB} 1, \mathrm{ABCG} 2$, Forkhead box protein M1 (FOXM1), and BMI-1, confer TNBCSCs resistance to chemotherapy ${ }^{[6,70]}$. Hh signaling also induces several EMT and invasiveness regulators including Snail family zinc finger 1 (SNAI1), Neuropilin 2 (NRP2), Cysteine-rich angiogenic inducer 61 (CYR61), Matrix metallopeptidase (MMP), and C-X-C chemokine receptor type 4 (CXCR4) ${ }^{[66]}$. As with Notch signaling, tumor-stroma interactions have been shown to sustain Hh signaling in TNBC promoting stemness ${ }^{[71]}$.

Paradoxically, hypoxia-induced Carbonic anhydrase Carbonic Anhydrase (CAXII), which is highly expressed in TNBC, negatively regulates Hh signaling ${ }^{[72]}$. Similarly, pluripotency factor NANOG, which is equally overexpressed in $\mathrm{TNBC}^{[73]}$, was found to inhibit Hh-induced transcription ${ }^{[74]}$. These findings perhaps emphasize the temporal, intentional and context-dependent nature of Hh regulation in TNBC. Further work is needed to fully understand the spatiotemporal dynamics of Hh regulation within TNBCSCs and the TNBC microenvironment.

\section{Growth factor and cytokine-driven pathways}

Guanine nucleotide exchange factor (GEF)-H1/PKD

The protein kinase $\mathrm{D}(\mathrm{PKD})$ family of actin remodeling proteins are well-characterized cell migration regulators in TNBC and other breast cancers ${ }^{[75-77]}$. PKD1 is the predominant isoform in non-malignant tissue where it maintains an epithelial phenotype. Upon oncogenic conversion, PKD1 is silenced via methylation inducing $\mathrm{EMT}^{[78]}$. Because they lack the expression of ER, a transcriptional repressor of PKD expression, TNBCs express high levels of $\mathrm{PKD} 2$ and $\mathrm{PKD} 3^{[79]}$. $\mathrm{PKD} 3$, especially, is associated with increased TNBC metastasis, proliferation, and stemness ${ }^{[78,80-82]}$. Recently, Lieb et al ${ }^{[80]}$ also demonstrated that upstream activation by Rho guanine nucleotide exchange factor 2 (GEF-H1) mediates PKD3 maintenance of TNBCSCs.

\section{JAK/STAT}

The JAK/STAT pathway is an evolutionarily conserved axis that plays a central role in several cellular processes including proliferation, motility, and stemness ${ }^{[83]}$. JAK/STAT signaling is initiated when a growthfactor or cytokine binds to a cell surface receptor containing a JAK binding site. JAK is recruited to the intracellular JAK binding site of the receptor where it is activated. Activated JAK then phosphorylates and activates a STAT transcription factor for downstream transactivation of target genes. During 
development, JAK/STAT is essential for several homeostatic processes including hematopoiesis, stem cell maintenance, and organogenesis ${ }^{[8,84]}$. It also plays a key role as a pluripotency mediator for somatic cell reprogramming ${ }^{[85]}$. Constitutive activation of JAK/STAT signaling has been well-characterized as a driving factor in several malignancies ${ }^{[86]}$. In breast cancer, JAK/STAT has been identified as a key regulator of CSC self-renewal and non-CSC cells' dedifferentiation into $\mathrm{CSCs}^{[87,88]}$.

Certain growth factors and cytokines that activate JAK/STAT have been identified as essential drivers of TNBC proliferation and stemness. These include IL6, Prostaglandin-I synthase (PTGIS), Hyaluronan synthase 1 (HAS1), C-X-C Motif Chemokine Ligand 3 (CXCL3), and 6-phosphofructo-2-kinase/fructose-2, 6-biphosphatase 3 (PFKFB3) ${ }^{[88]}$. Additionally, the IL-6/JAK2/STAT3 pathway is preferentially activated in TNBCSCs compared to non-TNBC BC and is associated with increased risk of metastasis ${ }^{[88]}$. Other cytokines including IL6, IL8, and CXCL1, which similarly drive JAK/STAT, are associated with increased growth and stemness in TNBC but not non-TNBC breast cancer ${ }^{[8,90]}$. Leptin, an energy homeostasis regulator enriched in TNBC, drives JAK2/STAT3 activity TNBCSCs, promoting stemness ${ }^{[91]}$. HN1L, an upstream regulator of STAT3, is also enriched in TNBC where it is associated with poor clinical outcomes, stemness, and motility ${ }^{[92]}$. This is mediated by its regulation of STAT3, LEPR, and pluripotency regulators $\mathrm{SOX} 2 / 9$ and $\mathrm{KLF}_{4}{ }^{[92]}$. Other chemokines including CCL5 have been shown to promote spheroid formation in TNBC via JAK/STAT ${ }^{[93]}$. IFN- $\beta$, which is repressed in TNBC, was also shown to negatively regulate TNBCSC formation via activation of STAT $1^{[94]}$. Intriguingly, in luminal breast cancers, IFN- $\beta$ promotes stemness via induction of SOX2 and STAT3 activity ${ }^{[95]}$. In TNBC, IFN- $\beta$ does not activate STAT3. This suggests IFN $-\beta$ regulation of stemness, and by extension general CSC regulation, is subtype-specific and context-dependent.

\section{Transforming growth factor beta and tumor necrosis factor}

Transforming growth factor beta (TGF- $\beta$ ) and tumor necrosis factor (TNF) are two important, antagonistic cytokines, which regulate a plethora of cellular activities including differentiation, survival, proliferation, and homeostasis ${ }^{[96]}$. They have been implicated in the progression of several cancers ${ }^{[97]}$.

TGF- $\beta$ is important for early mammary development, regulating morphogenesis via specific regulation of ECM remodeling, and epithelial cell growth and differentiation ${ }^{[98]}$. Its role in breast cancer, however, is a lot more complex. Early in breast cancer development, TGF- $\beta$ inhibits cell growth and promotes apoptosis. In later stages, it promotes proliferation, invasiveness, and stemness ${ }^{[99]}$. TGF- $\beta$ also promotes EMT in breast and other cancers via activation of downstream transcriptional effectors small mothers against decapentaplegic (SMAD), SNAIL, Zinc-finger E homeobox-binding family (ZEB), and TWIST ${ }^{[100-103]}$. Shipitsin et al ${ }^{[104]}$ showed that TGF- $\beta$ is preferentially expressed in ER- CSCs where it regulates differentiation into an epithelial phenotype. In TNBC, treatment with chemotherapeutic agent paclitaxel causes hyperactivation of autocrine TGF- $\beta$ signaling, promoting therapy resistance and relapse ${ }^{[105]}$. TGF- $\beta$ also directly regulates the expression of Wnt5a promoting stemness and proliferation ${ }^{[106]}$. TGF- $\beta$ is often enriched in the TNBC microenvironment and can be produced by infiltrating stromal and immune cell populations ${ }^{[107]}$. These studies suggest TGF- $\beta$-induced CSC accumulation as a drug resistance mechanism in TNBC.

$\mathrm{TNF} \alpha$ is an inflammatory cytokine secreted predominantly by activated macrophages, natural killer cells, MDSCs, and T-cells in the $\mathrm{TME}^{[97,108]}$. Although initially thought to be an effector for anti-tumor immunity, $\mathrm{TNF} \alpha$ has been shown to have some pro-tumor functions. TNF $\alpha$ promotes plasticity, angiogenesis, and CSCs in breast cancer ${ }^{[109]}$. TNF $\alpha$ secreted by tumor-associated-macrophages has also been shown to induce EMT and stemness pathways via activation of NF- $\mathrm{B}$ (Nuclear factor kappa-light-chain-enhancer of activated B cells $)^{[110]}$. Liu et al. ${ }^{[11]}$ demonstrated that TNF $\alpha$ increases TNBCSCs via the upregulation of TAZ and NF- $\kappa$ B. These findings closely mirror works from Storci et al. ${ }^{[12]}$ and Li et al. ${ }^{[113]}$, who showed 
that TNF $\alpha$ increases CSCs and EMT in TNBC via upregulation of SNAIL-related zinc-finger transcription factor (SLUG) and TWIST. Altogether, these studies suggest a vital role for inflammatory cytokines secreted by tumor and infiltrating immune cells in regulating stemness and self-renewal in TNBC.

\section{PI3K/protein kinase B/mechanistic target of rapamycin kinase(mTOR)}

The PI3K/Protein Kinase B (AKT) pathway is a ubiquitous growth pathway that regulates cell proliferation, survival, motility, and differentiation in most tissue types ${ }^{[114]}$. PI3K/AKT hyperactivity has been associated with the progression of several cancers ${ }^{[114]}$. Recent studies have also linked aberrant PI3K/AKT activation to breast cancer stemness ${ }^{[115,116]}$. PI3K/AKT signaling results in phosphorylation and activation of AKT by mTOR and PDK1. Activated AKT regulates downstream effectors such as cAMP response elementbinding protein (CREB), Forkhead box protein O1 (FOXO), p27, and mTOR, driving growth and motility. Phosphatase and tensin homolog (PTEN) directly antagonizes AKT activation regulating the pathway ${ }^{[117]}$. In TNBC, loss-of-function mutations to PTEN and gain-of-function mutations to PI3K drive an especially hyperactive PI3K/AKT phenotype ${ }^{[118]}$. This phenotype drives tumor heterogeneity and CSC accumulation via induction of a "fibroblast-like" state ${ }^{[119]}$. TNBCSCs also express higher levels of mTORC1 compared to the bulk of the tumor contributing to self-renewal and growth ${ }^{[120]}$. SRC Proto-Oncogene, Non-Receptor Tyrosine Kinase (SRC) kinase, which is an upstream activator of PI3K/AKT, induces TNBCSC enrichment and resistance to therapy ${ }^{[121]}$. HIF- $2 \alpha$ drives TNBCSCs activation via induction of CD44 and PI3K/AKT/ mTOR signaling ${ }^{[115]}$. Intriguingly, Britschgi et al. ${ }^{[122]}$ showed that inhibition of PI3K/AKT/mTOR in TNBC could inadvertently induce IL8 secretion and activate a JAK2/STAT5 axis which promotes stemness and metastases. This suggests compensatory signaling mechanisms might play a bigger role than previously thought in driving CSCs.

\section{EMT regulators}

Phenotypic plasticity is the most characteristic feature of CSCs. These tumor-initiating cells reserve the ability to switch from a quiescent, epithelial state to a motile, drug-resistant mesenchymal phenotype capable of invading other tissues and re-seeding tumors ${ }^{[109]}$. EMT is thus a key feature of CSCs, and several EMT regulators, mostly transcription factors, play important roles in regulating CSC function. Several of these regulators, including downstream transcriptional effectors for Wnt ( $\beta$-catenin/LEF/TCF), Notch (NCID/CSL), Hh (GLI), and TNF/TGF- $\beta$, are discussed above.

SNAIL

Wnt/ $\beta$-catenin signaling induces SNAIL accumulation. SNAIL mediates E-cadherin repression, inducing $\mathrm{EMT}^{[123]}$. In TNBC, SNAIL is associated with relapse, chemoresistance, and metastases ${ }^{[124]}$. SNAIL also regulates IL-8 expression, which promotes stemness in TNBC ${ }^{[125]}$. A SNAIL-G9A-DNMT1 complex also epigenetically silences Fructose-Bisphosphatase 1 (FBP1) in TNBCSCs, inducing metabolic reprogramming increasing glucose uptake and ATP production even under hypoxia ${ }^{[126]}$. The SNAIL-induced glycolytic switch to a more "Warburg"-like state reduces oxygen consumption and reactive oxygen species (ROS) accumulation, promoting tumorigenesis, survival, and self-renewal ${ }^{[126]}$. Recent work by Zhang et al. ${ }^{[25]}$ suggests uncoupling Protein 1 (UCP1), which is downregulated in TNBC, represses SNAIL-mediated FBP1 silencing, suppressing TNBCSC accumulation. BRD4 also promotes SNAIL expression in TNBC, conferring TNBC cells with stem-cell-like traits ${ }^{[127]}$.

\section{$Z E B$}

ZEB is another key transcriptional regulator of EMT and stemness. Similar to SNAIL and other EMT regulators, it represses E-cadherin and is induced by several stemness-associated signaling pathways including Wnt/ $\beta$-catenin and cytokine signaling ${ }^{[123]}$. Pioneering work by Chaffer et al ${ }^{[26]}$ suggests ZEB1 is a CSC-switch in TNBC. TNBC cells maintain the ZEB1 promoter in a bivalent chromatin configuration allowing them to quickly respond to microenvironmental cues, modulating ZEB1 expression to switch 
between non-CSC and CSC phenotypes. This challenges the current dogma of CSC activity that suggests CSCs give rise to non-CSC cells in a unidirectional manner. Instead, TNBCSCs and non-CSC TNBC cells reserve the ability to switch between stem cell and non-stem cell phenotypes depending on environmental stimuli. Intriguingly, this interconversion was not found in other non-TNBC breast cancer subtypes, suggesting ZEB1 modulation as a key mechanism for the problematic tumorigenicity of TNBCs. Feldker et al. ${ }^{[128]}$ also showed that ZEB1 forms a transactivation complex with AP-1 factors FOS like 1, AP-1 transcription factor subunit (FOSL1), JUN, and Hippo pathway effector YAP in TNBC cells, promoting stemness genes' expression.

\section{TWIST}

TWIST is the third major transcriptional regulator of EMT. TWIST regulates stemness in TNBC by downregulating $\mathrm{CD} 24$, inducing the accumulation of $\mathrm{CD} 44^{+} \mathrm{CD} 24 \mathrm{ALDH}^{+} \mathrm{TNBCSCs}^{[27]}$. Additionally, a TWIST/BRD4 complex induces IL31RA expression in TNBC cells, promoting stemness via IL31 ${ }^{[129]}$. A similar TWIST/BRD4 complex transcribes WNT5A in TNBC, promoting stem-cell-like properties and tumorigenicity ${ }^{[130]}$. In TNBC, deubiquitinating enzyme ubiquitin-specific protease 2 (USP2) promotes TWIST stabilization, allowing it to induce stemness, EMT, and chemoresistance ${ }^{[131]}$. TWIST also increases the expression of drug efflux pumps in TNBCSCs, promoting chemoresistance ${ }^{[27]}$.

\section{Hypoxia}

Hypoxia is a vital contributing factor to CSC generation and maintenance. Hypoxia is a hallmark of the TME in several cancers, and it drives CSC accumulation via the activity of Hypoxia-Inducible Factor (HIF) transcription factors ${ }^{[30,132]}$. HIFs normally function to maintain oxygen homeostasis, preventing excessive production of toxic $\operatorname{ROS}^{[132]}$. The TNBC TME is highly hypoxic ${ }^{[58]}$. Treatment with chemotherapeutic agents such as paclitaxel and gemcitabine exacerbates hypoxia in the TNBC TME, inducing HIF activity ${ }^{[30,133]}$. These HIFs promote TNBCSC accumulation via induction of IL- 6 and IL- 8 signaling and increased $\mathrm{MDR}^{\left[{ }^{[30]}\right.}$. Additionally, HIFs regulate the production of Colony Stimulating Factor 1 (CSF1) in TNBCs, which recruits tumor-associated macrophages and myeloid-derived suppressor cells to the $\mathrm{TME}^{[134]}$. In the TNBC TME, these pro-tumor immune cell types secrete cytokines such as TGF- $\beta$ and tumor necrosis factor (TNF- $\alpha$ ), which drive stemness and metastases, as discussed above ${ }^{[134]}$. HIF- 1 also transcribes CD47 in TNBCSCs; CD47 allows TNBCSCs to evade phagocytosis by macrophages ${ }^{[135]}$. HIF-1 also promotes the expression of Glutamate-Cysteine Ligase Modifier Subunit which inhibits mitogen-activated protein kinase kinase (MEK)/extracellular-signal-regulated kinase (ERK) signaling in TNBC cells. Loss of MEK/ ERK signaling promotes nuclear translocation of $\mathrm{FOXO}$, which transcribes and activates TNBCSC and pluripotency mediator $\mathrm{NANOG}^{[133]}$. Similar findings by Lan et al. ${ }^{[136]}$ suggest HIF-1-induced A2BR activates Protein kinase C delta type (PKC- $\delta$ )/STAT3 to transcribe IL-6 and NANOG promoting stemness in TNBC. HIF-1 also directly transcribes TAZ, which induces TNBCSCs ${ }^{[137]}$. Work by Lee et al. ${ }^{[29]}$ also suggests amplified MYC and MCL1 in TNBC drive the production of ROS, which in turn induce HIF-1 $\alpha$, promoting stemness and chemoresistance.

Carbonic anhydrase CAIX is another hypoxia-induced factor directly regulated by HIF allowing cancer cells to regulate intracellular $\mathrm{pH}$ during hypoxia ${ }^{[138]}$. It is highly expressed in TNBC where it correlates with poor survival and metastases as well as promotes TNBCSC survival and stemness ${ }^{[138-140]}$.

\section{OTHER TRANSCRIPTION REGULATORS OF TNBC STEMNESS}

\section{Pluripotency regulators}

Pluripotency is a common feature of both CSCs and normal stem cells. During development, pluripotency is maintained and induced by a group of transcription factors regulated by environmental clues to create varied cell and tissue lineages ${ }^{[141]}$. Ectopic overexpression of these transcription factors, including OCT4, SOX2, NANOG, KLF4, and MYC, on non-malignant somatic cells can reprogram them into pluripotent 
stem cells ${ }^{[141,142]}$. Perhaps unsurprisingly, TNBC and other tumors similarly overexpress these factors to promote pluripotency and self-renewal.

OCT4 was first identified as an essential regulator of pluripotency and self-renewal in the embryo during development ${ }^{[143]}$. It has since been identified as a significant oncogene promoting stemness, self-renewal, and tumor recurrence ${ }^{[144]}$. OCT4 is overexpressed in TNBC where it correlates with worse clinical outcomes ${ }^{[28]}$. Cheng et al. ${ }^{[145]}$ showed that STAT3 drives OCT4 and MYC expression in TNBCSCs increasing chemoresistance and TNBCSC accumulation. Thiagarajan et al. ${ }^{[91]}$ further demonstrated that leptin induced STAT3 promotion of OCT4 expression was specific to TNBCSCs and not non-CSC TNBC cells. Lu et al. ${ }^{[133]}$ also showed that chemotherapy induces a HIF/S100A10/KDM6A axis which promotes OCT4 expression and stemness in TNBC. Interestingly, emerging work from Jin et al ${ }^{[146]}$ recently suggests OCT4 can suppress EMT in both TNBC and Luminal cancers via activation of STAT3. This suggests potential bimodal regulation of stemness and self-renewal by OCT4.

SOX2 is another regulator of stem cell pluripotency during embryonic development ${ }^{[141]}$. SOX2 is overexpressed in TNBC where it correlates with increased proliferation, metastasis, and worse clinical outcomes $^{[147,148]}$. Mukherjee et al ${ }^{[149]}$ found that SOX2 was increased in TNBCSCs induced by chemotherapy, promoting resistance and survival. Jung et al. ${ }^{[150]}$ showed that, in TNBC, SOX2 activity is predominantly localized to TNBCSCs. SOX2 upregulation in TNBCSCs might be mediated by an IMP3/SLUG signaling axis which transcribes SOX2 specifically in TNBC ${ }^{[151]}$. VEGF, a potent angiogenic factor in the TME, also drives TNBCSC accumulation and activity by promoting VEGF/STAT3 transcription of SOX2 and MYC $^{[152]}$. LIPH was also shown to regulate SOX2 in TNBCSCs, promoting metastasis ${ }^{[153]}$.

NANOG is a master regulator of self-renewal and pluripotency highly expressed in early life but silenced in adult somatic cells ${ }^{[154]}$. In several cancers, aberrant reactivation of NANOG contributes to tumorigenicity and stemness ${ }^{[141]}$. NANOG has been linked with increased stemness and poorer clinical outcomes in TNBC ${ }^{[155,156]}$. Paradoxically, in a follow-up study, Nagata et al. ${ }^{[73]}$ found NANOG to be a favorable prognostic marker for TNBC. This suggests NANOG might not be a reliable biomarker for TNBC. It is, however, a key driver of TNBC stemness, self-renewal, and metastasis ${ }^{[155,157]}$. NANOG overexpression in TNBC is driven by $338 \gamma$ MAPK activation, resulting in c-JUN/AP-1 transcription of the NANOG gene ${ }^{[157]}$. Thiagarajan et al. ${ }^{[155]}$ also showed that Cx26 forms a signaling complex with NANOG and FAK, stabilizing NANOG driving stemness. The formation of this complex was specific to TNBC and not present in nonTNBC cells. As mentioned above, HIF- 1 activity also directly induces NANOG transcription in TNBCSCs via MEK/ERK/FOXO3 and PKC- $\delta / \mathrm{STAT}^{[133,136]}$.

KLF4 is another important transcription factor during development. In tumors, it has been shown to have both oncogenic and anti-cancer roles ${ }^{[158]}$. In TNBC, its role appears to be equally confounding. Nagata et al. ${ }^{[73,159]}$ showed it is predominantly tumor-suppressive and associated with favorable clinical outcomes in TNBC by suppressing EMT. However, Yu et al. ${ }^{[56]}$ showed it is essential for the maintenance of TNBCSCs and TNBC migration and invasion. Zhou et al. ${ }^{[160]}$ also showed that KLF4 accumulation in TNBC is sustained by Protein arginine methyltransferase 5 (PRMT5) -mediated methylation, which prevents KLF4 degradation. Accumulation of KLF4 promotes TNBCSC expansion and survival ${ }^{[160]}$. Sharma et al. ${ }^{[161]}$ similarly demonstrated that KLF4 is predominantly expressed in TNBCSCs where it promotes survival, self-renewal, and chemoresistance. They also showed receptor tyrosine kinase (RTK) is a transcriptional target of KLF4 in TNBC, partially contributing to the chemoresistance phenotype ${ }^{[161]}$.

The MYC family of pro-oncogenic transcription factors are ubiquitous gene regulators that regulate several cellular processes including motility, survival, stemness, therapy resistance, and differentiation ${ }^{[162]}$. In several cancers, they are constitutively activated, driving hyperproliferative phenotypes ${ }^{[162]}$. In TNBC, 
MYC is highly expressed in CSCs where it drives self-renewal and chemoresistance ${ }^{[29,163,164]}$. Yin et al ${ }^{[164]}$ showed that MYC drives accumulation of TNBCSCs and induction of EMT in TNBC. Lee et al. ${ }^{[29]}$ showed that MYC, in concert with MCL1, promotes mitochondrial oxidative phosphorylation, which induces HIF 1 to promote TNBCSC accumulation and chemoresistance. In TNBC, high MYC levels are driven by a vascular endothelial growth factor receptor(VEGFR) -2/STAT3 axis, which transcribes MYC and SOX2 to promote stemness ${ }^{[152]}$. Lee et al. ${ }^{[165]}$ also showed that Hsp90 $\alpha$ promotes nuclear translocation of c-MYC to transcribe CSC-mediator BMI-1 in TNBCSCs. ID proteins were also shown to activate MYC in TNBCSCs via negative regulation of Roundabout homolog 1 (ROBO1 $)^{[166]}$. As mentioned above, WNT signaling also promotes MYC and Cyclin D1 expression in CSCs driving self-renewal ${ }^{[37]}$.

\section{Runt-related transcription factor}

The Runt-related transcription factor (RUNX) family of transcription factors regulate a plethora of developmental processes including cell growth, differentiation, and lineage specification ${ }^{[167]}$. During mammary development, RUNX factors are important for the maintenance of mammary epithelium homeostasis ${ }^{[168]}$. Work from Fritz et al. ${ }^{[169]}$ suggests RUNX factors drive EMT and stemness in breast cancer CSCs. In TNBC, RUNX1 is an independent prognostic indicator of poor patient outcomes ${ }^{[170]}$. In TNBCSCs, RUNX transcription factors and their coregulator CBF $\beta$ promote phenotypic plasticity and are essential for maintaining of the mesenchymal, invasive phenotype ${ }^{[171]}$. RUNX1 was also recently shown to regulate R-Spondin 3 (RSPO3) in TNBCSCs, promoting EMT, motility and stemness ${ }^{[172]}$. Accumulating evidence also suggests significant interaction between RUNX factors and the hippo pathway, an established self-renewal signaling axis in $\mathrm{TNBC}^{[173]}$.

\section{Hippo YAP/TAZ}

The Hippo pathway is a key regulatory axis for cell fate, organ development, tissue regeneration, and selfrenewal during development ${ }^{[174]}$. It consists of a cytoplasmic kinase module composed of mammalian Ste20-like kinases (MST1/2), which, in response to environmental cues, phosphorylates and activates LATS1/2 kinases. Activated LATS1/2 phosphorylates and inactivates an oncogenic transcriptional module consisting of YAP, TAZ, and TEA Domain family member (TEAD), promoting their retention and subsequent degradation in the cytoplasm. When the hippo kinase module is "off", YAP/TAZ translocates to the nucleus and induces transcription of TEAD target genes ${ }^{[23,174]}$.

Aberrations in Hippo signaling have been shown to induce dedifferentiation of mature cells into progenitor cells $^{[175]}$. It has also been associated with induction of CSC accumulation in various cancers. In breast cancers, TAZ confers CSCs self-renewal and tumor-initiation capacities ${ }^{[176]}$. In TNBC cells, YAP has been shown to regulate the transcription of stem cell signature genes, promoting tumorsphere formation ${ }^{[177]}$. Guo et al. ${ }^{[178]}$ demonstrated that YAP promotes chemoresistance in TNBC. Aberrant regulation of YAP/TAZ in TNBC is mediated by the activity of an SRF-IL6 axis and glucocorticoid receptor signaling ${ }^{[177,179]}$. KIBRA, a tumor suppressor, also inhibits YAP/TAZ activation but is silenced in TNBC by chromosomal mutation ${ }^{[180]}$. USP1 also promotes TAZ stability by deubiquitination in TNBC, promoting proliferation and metastasis ${ }^{[181]}$. YAP/ TAZ signaling is also induced by several pathways discussed in previous sections: ROR $1 / 2$ activate YAP signaling; ZEB complexes with YAP to drive stemness; and HIF and TNF induce TAZ.

\section{$N F-\kappa B$}

The NF- $\mathrm{B}$ transcriptional complex is a highly conserved transcriptional complex that regulates cell survival, growth, differentiation, and cytokine production ${ }^{[182]}$. It regulates gene expression in response to a plethora of extracellular stimuli including cytokines, free radicals, and pathologic antigens, among others $^{[182]}$. The NF- $\kappa$ B family consists of five transcription factors: RelA, RelB, c-Rel, NF- $\kappa B 1$, and NF- $\kappa \mathrm{B} 2$. Deregulated NF- $\kappa B$ activity has been associated with tumorigenesis in several cancers ${ }^{[182]}$. 
In breast cancer, TNBCs exhibit the highest levels of constitutively activated $\mathrm{NF}-\kappa^{[1833]}$. Activated NF- $\kappa \mathrm{B}$ drives accumulation of TNBCSCs via induction of JAG1/NOTCH signaling ${ }^{[183]}$. This mechanism of CSC accumulation was found to be exclusive to TNBCs and not other breast cancers. Hossain et al. ${ }^{[184]}$ also showed that JAG1/NOTCH signaling in turn promotes NF- $\kappa \mathrm{B}$ activity in TNBCSCs to transcribe antiapoptosis gene cIAP-2. These findings suggest a dynamic, cyclical, NF- $\kappa \mathrm{B}-J A G 1 / \mathrm{NOTCH}-\mathrm{NF}-\kappa \mathrm{B}$ signaling axis maintains TNBCSCs accumulation and survival in TNBCs. Intriguingly, the NF- $\mathrm{KB}$ inhibitor IKK $\varepsilon$ was also suggested as a key mediator of TNBCSC accumulation ${ }^{[185]}$. In concordance with these findings, Kim et al. ${ }^{[87,177]}$ and Barbie et al. ${ }^{[93]}$, showed that IKKe expression marks a population in TNBCs with high IL-6, a cytokine previously shown to promote stemness.

\section{IDENTIFYING NEW TNBCSC REGULATORS}

Significant leaps have been made in recent years developing bioinformatic tools to analyze and characterize heterogeneous tissue types. One such emerging technique, single cell RNA-sequencing (scRNA-seq), allows investigators to probe gene expression at the single cell level, identifying novel cell types and conserved biomarkers that drive their phenotype. ScRNA-seq has been used to identify novel, self-renewing CSC populations in several cancers ${ }^{[186-188]}$. We sought to similarly identify CSC populations within publicly available breast cancer scRNA-seq data, to demonstrate how high throughput scRNA-seq data can be used to identify new TNBCSC regulators.

scRNA-seq data from Yeo et al. ${ }^{[189]}$ profile the transcriptomes of over 13,000 cells from multiple mice models of breast cancer including TNBC(NCBI Geo accession number: GSE123366). Detailed methods on how the samples were prepared and data acquired can be found in ${ }^{[189]}$. Briefly, following tumor excision and dissociation into single-cell suspensions, breast epithelial cells were sorted via FACS and sequenced with the Chromium 10X droplet-based scRNA-seq platform. Library generation was performed using the 10X Chromium single-cell kit and pooled libraries sequenced using the Illumina HiSeq 2500 platform. Raw sequencing data were processed and normalized using the Cell Ranger Single Cell Software Suite. Cells with high mitochondrial gene ratio ( $>20 \%)$ and low/high gene expression $(<500$ genes; $>1000$ genes) were excluded from the analysis.

We analyzed the raw scRNA-seq matrix file deposited by the authors on NCBI GEO (GSE123366) using the Seurat package in $\mathrm{R}^{[190]}$. Data were fed into $\mathrm{R}$ as a counts matrix file, scaled by a factor of 10,000 , and normalized by $\log$ transform. We further trimmed the data excluding cells with a mitochondrial ratio > $5 \%$ and included cells with more than 200 but fewer than 6000 genes expressed. In total, 13,412 cells were recovered after our trimming. Using Seurat's IntegrateData function, the cells from all conditions were integrated into one analysis. Clustering was performed with the run principal component analysis in seurat (RunPCA) function using the first 20 principal components and visualized using uniform manifold approximation and projection (UMAP). Twelve distinct clusters were identified [Figure 2A]. To identify CSC populations, we profiled the expression of $\mathrm{CD} 44(\mathrm{Cd} 44)$ and $\mathrm{CD} 24(\mathrm{Cd} 24 \mathrm{a})$ using dot, feature, violin, and ridge plots [Figure $2 \mathrm{~B}-\mathrm{F}$ ]. We identified one small cluster (Cluster 11 ) as the only $\mathrm{CD} 44^{+} \mathrm{CD} 24^{-}$cluster. Using the FindAllMarkers function, we identified genes specifically expressed/upregulated in Cluster 11 compared to other cells in the analysis [Table 1].

Several genes identified as Cluster 11 markers have been described as CSC regulators in TNBC and other cancers. PCDH7 was shown to promote stemness and brain metastasis in TNBCSCs ${ }^{[191]}$. Array data from da Silveira et al. ${ }^{[192]}$ suggest transcription factor CREB3L1 is upregulated in breast cancer CSCs compared to the bulk of the tumor. MMP14 expression was shown to be double in TNBCSCs compared to the bulk of the tumor population ${ }^{[193]}$. Kulesza et al ${ }^{[194]}$ found SERPINA3 to be overexpressed in melanoma CSCs where it promotes metastasis and invasion. Oktem et al. ${ }^{[195]}$ showed that VCAN is increased in prostate CSCs, especially when maintained as spheroids. MARCKS1, induced by LncZi2, was shown to promote 
A

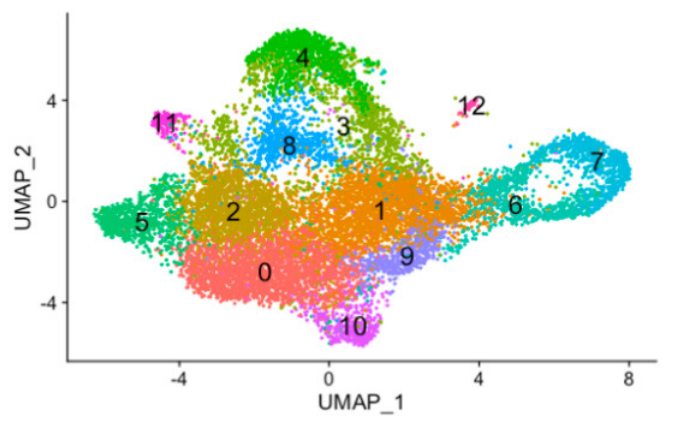

C

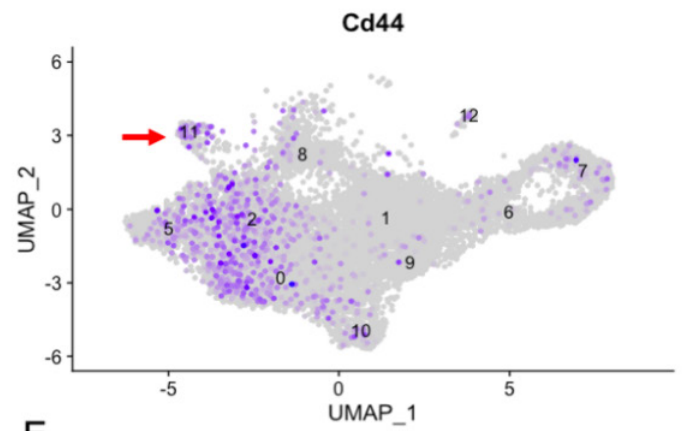

$\mathrm{E}$

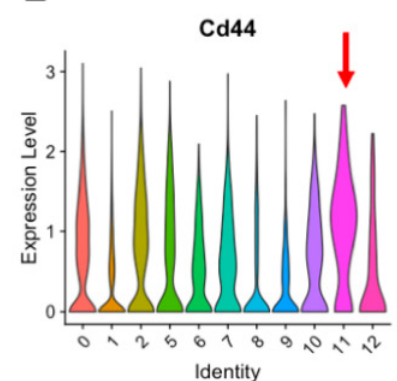

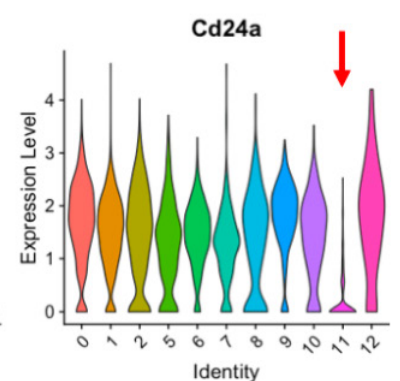

B
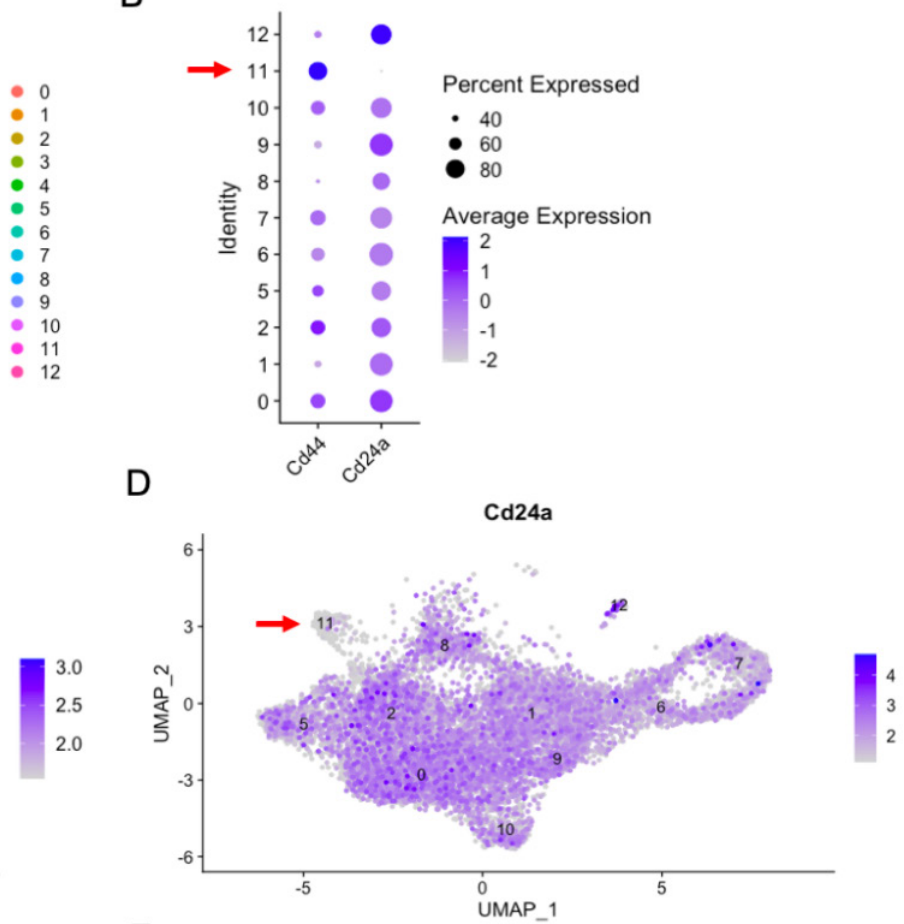

$\mathrm{F}$
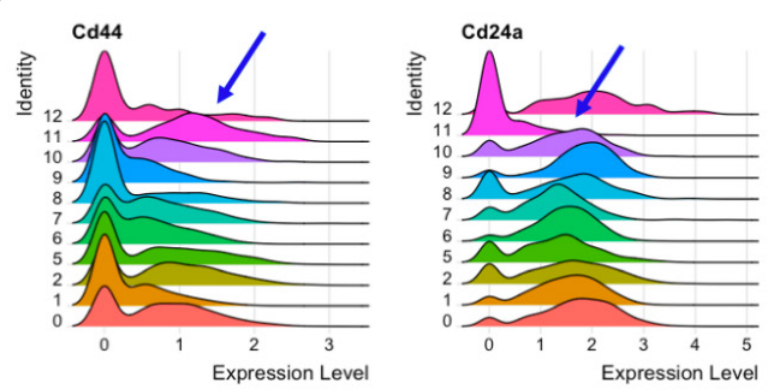

Figure 2. Red and blue arrows indicate putative CD44 $4^{\text {-high }} / \mathrm{CD} 24^{\text {-low }}$ CSC cluster (Cluster 11). (A) Combined Seurat analysis of 13,412 cells shown in UMAP projection plot showing the individual clusters identified in GSE123366; (B) dot plot visualizing CD44 and CD24 expression in the individual clusters; (C, D) feature plots showing CD44 and CD24 expression in individual cells; and (E, F) violin and ridge plots showing distribution of CD44 and CD24 expression in Seurat clusters, respectively

self-renewal and accumulation of liver CSCs ${ }^{[196]}$. In glioma CSCs, VASN was found to be a critical link between hypoxia and Notch signaling to maintain $\mathrm{CSCs}^{[197]}$. UDPH has also been linked to prostate cancer stemness ${ }^{[198]}$.

Several of the markers we identified in our analysis have not been described within the context of CSCs or TNBCSCs. Transcription factors such as CREB3L1 and SERPINA3 are especially attractive as potential TNBCSC regulators because they could directly regulate the expression of known stemness genes. Further work investigating the chromatin binding activity of these factors to determine their target genes in TNBCSCs is necessary to characterize their role in stemness.

\section{EPIGENETIC REGULATORS OF STEMNESS IN TNBC}

The epigenome is a crucial component of cell identity. Precise regulation of the epigenome in early development and throughout life is essential for determining cell fate, tissue patterning, and organogenesis. Epigenetic mechanisms including DNA methylation, chromatin modifications, and RNA interference 
Table 1. Top 30 genes upregulated in CD44 ${ }^{\text {-high }} /$ CD24 ${ }^{\text {-low }}$ cluster (Cluster 11). The genes were obtained using the Finallmarkers function from the Seurat package with expression threshold set at 0.25 .

\begin{tabular}{|c|c|}
\hline Gene & $P$ value \\
\hline Pcdh7 & $1.09 \mathrm{E}-150$ \\
\hline Den & 5.55E-119 \\
\hline Plpp3 & $3.19 E-106$ \\
\hline Creb3l1 & $3.22 \mathrm{E}-104$ \\
\hline Hexa & $7.26 \mathrm{E}-94$ \\
\hline Ppic & $4.18 \mathrm{E}-87$ \\
\hline Serpina3n & $2.91 E-85$ \\
\hline Mmp14 & $9.55 \mathrm{E}-80$ \\
\hline Snhg18 & $1.01 E-75$ \\
\hline Vcan & $1.97 \mathrm{E}-75$ \\
\hline Ifitm2 & $3.08 \mathrm{E}-74$ \\
\hline Col4a1 & $1.59 \mathrm{E}-73$ \\
\hline Gstm2 & $8.51 \mathrm{E}-65$ \\
\hline Serf2 & $5.42 \mathrm{E}-60$ \\
\hline Calu & $1.40 \mathrm{E}-54$ \\
\hline Marcks & $2.86 \mathrm{E}-51$ \\
\hline Bmp1 & 7.37E-50 \\
\hline Selenof & $2.12 E-49$ \\
\hline $\operatorname{Itm} 2 c$ & $1.42 \mathrm{E}-41$ \\
\hline Rrbp1 & $2.50 \mathrm{E}-40$ \\
\hline Vasn & $3.81 E-38$ \\
\hline Col27a1 & $1.73 E-37$ \\
\hline Ugdh & $2.18 \mathrm{E}-37$ \\
\hline $116 s t$ & $1.15 E-31$ \\
\hline Ckap4 & $3.62 \mathrm{E}-30$ \\
\hline Vat1 & $4.21 \mathrm{E}-30$ \\
\hline Lamc1 & $9.67 \mathrm{E}-30$ \\
\hline Pdia3 & $6.54 \mathrm{E}-26$ \\
\hline Cyth3 & 8.66E-19 \\
\hline
\end{tabular}

Pcdh7: Protocadherin-7; Dcn: decorin; Plpp3: phospholipid phosphatase 3; Creb311: CAMP responsive element binding protein 3 like 1; Hexa: hexosaminidase A; Ppic: peptidylprolyl isomerase C; Serpina3n: serine protease inhibitor A3N precursor; Mmp14-matrix metallopeptidase 14; Snhg18: small nucleolar RNA host Gene 18; Vcan: versican; Ifitm2: interferon induced transmembrane protein 2; Col4a1: collagen alpha-1(IV); Gstm2: glutathione S-transferase mu 2; Serf2: small EDRK-rich factor 2; Calu: calumenin; Marcks: myristoylated alanine rich protein kinase C substrate; Bmp-1 Bone morphogenetic protein-1; Selenof: selenoprotein F precursor; Itm2c: integral membrane protein 2C; Rrbp1: ribosome-binding protein 1; Vasn: vasorin; col27a1: collagen alpha-1 (XXVII); Ugdh: UDP-glucose dehydrogenase; Il6st: interleukin 6 signal transducer; Ckap4: cytoskeleton associated protein 4; Vat1: vesicle amine transport 1; Lamc1: laminin subunit gamma-1; Pdia3: protein disulfide-isomerase A3; Cyth3: cytohesin-3

have all been shown to play a role in regulating cell growth and pluripotency ${ }^{[18,199,200]}$. Deregulations in these mechanisms, especially at loci of growth and pluripotency related genes, have been associated with tumorigenesis and stemness in several cancers ${ }^{[18,199-201]}$. In TNBC, aberrations in epigenetic mechanisms are key contributing factors to the highly heterogeneous and stem cell-like phenotype often seen in patients ${ }^{[199,202]}$.

DNA methylation is significantly deregulated in most breast cancers including TNBC ${ }^{[200,203]}$. A comprehensive analysis of the TNBC methylome by Stirzaker et al. ${ }^{[203]}$ showed that hypermethylation in TNBC correlates with worse patient outcomes. Kagara et al. ${ }^{[201]}$ demonstrated that, in TNBC, hypomethylation of the promoter regions for CSC markers CD44, CD133, and Musashi-1 drove increased expression, contributing to stemness. Hypomethylation of these genes was specific to TNBC and correlated with a clinically aggressive phenotype ${ }^{[201]}$. Arginine methyltransferase PRMT1 was also shown to promote TNBC stemness, potentially via activation of STAT3 ${ }^{[204]}$. Methylation of the gene for scaffold protein DAB2IP was also shown to be essential for TNBCSCs accumulation. Treatment with DNA methylation inhibitor decitabine reversed the hypermethylation phenotype, rescuing DAB2IP expression and reducing 
stemness ${ }^{[205]}$. Bao et al. ${ }^{[206]}$ also showed that TET1 and $5 \mathrm{hmC}$ are essential for $\mathrm{H}_{2} \mathrm{O}_{2}$-dependent self-renewal and accumulation of TNBCSCs.

Deregulated chromatin architecture is a feature of several cancers ${ }^{[207]}$. Histone modifications at loci of pluripotency and stemness genes can promote stem cell accumulation in $\mathrm{TNBC}^{[200]}$. Li et al ${ }^{[200]}$ showed that histone methylation profiles for TNBCSCs differ starkly from non-CSC TNBC cells. H3K4me2 and H3K27me3 methylation of genes in stemness pathways Wnt and GnRH differed significantly in TNBCSC, potentially driving deregulated pathway activity ${ }^{[200]}$. Histone methyltransferase EZH2 was shown to maintain stemness and metastasis in TNBCSCs. Inhibition of EZH2 differentiated TNBCSCs into a luminal-like phenotype which was more sensitive to endocrine therapy ${ }^{[208]}$. Histone deacetylases (HDAC) HDAC 1 and HDAC7 have also been shown to be specifically overexpressed in TNBCSCs compared to nonCSC tumor cells ${ }^{[209]}$. Caslini et al. ${ }^{[210]}$ later showed that HDAC7 binds and regulates transcription start sites for CSC genes including c-MYC, CD44, SLUG, and SMAD3. In studies by both Witt et al. ${ }^{[209]}$ and Caslini et al. ${ }^{[210]}$, HDAC inhibition with clinically available HDAC inhibitors could be used to target CSCs. Su et al. ${ }^{[211]}$ similarly showed that HDAC inhibitors could reprogram TNBCSCs into a less aggressive phenotype. Recent work from Darvin et al. ${ }^{[212]}$ suggests increased expression of HDACs in CSCs drives EMT-induced PD-L1 expression in BT-549 TNBCSCs. They also found reduced distribution of hypermethylated, repressive histones $\mathrm{H}_{3} \mathrm{~K} 9 \mathrm{me} 3$ and $\mathrm{H}_{3} \mathrm{~K}_{2} 7 \mathrm{me} 3$ at the promoter for PD-L1, partially contributing to high $\mathrm{PD}-\mathrm{L} 1$ expression in $\mathrm{CSCs}^{[212]}$. Torres et al. ${ }^{[213]}$ also found that linker histone $\mathrm{H} 1.0$ regulates the differentiation state of cells within several tumors including TNBC with H1.0-low cells being pluripotent and stem-cell-like.

Deregulation in mechanisms of RNA interference, predominantly microRNAs (miRNA), can similarly contribute to CSC accumulation in TNBC. Li et al. ${ }^{[214]}$ identified a six-miRNA gene signature that regulates TNBCSC response to chemotherapeutic stress. Chemotherapeutic stress drove increased stemness and self-renewal in TNBCSCs, partially via modulation of these miRNAs, including miR-193a-5p, miR-92a-3p, miR-192-5p, miR-375, miR-155-5p, and miR-21-3p. MiR-34a was also shown to repress stemness in TNBC by targeting IMP3, a ribonucleoprotein highly expressed in breast cancer and TNBC CSCs ${ }^{[215]}$. Sun et al. ${ }^{[216]}$ showed that miR-223 is downregulated in TNBCSCs compared to non-CSC cells and functioned as a negative regulator of TNBCSC survival. MiR-203 is a well-characterized regulator of stemness and EMT in TNBC. It suppresses EMT, colony formation, and proliferation by targeting TP63 ${ }^{[217]}$. Subsequent work suggests miR-203 is epigenetically silenced in TNBC, specifically via DNA methylation ${ }^{[218]}$. Wellner et al.$^{[219]}$ further demonstrated that miR-203 is one of several miRNAs repressed by stemness transcription factor ZEB1 to promote CSC self-renewal. MiR-205 is another negative regulator of stemness in TNBC which targets ZEB1/2 and is repressed by Notch signaling ${ }^{[220,221]}$. Dong et al. ${ }^{[222]}$ demonstrated miR-139 suppresses tumorigenicity in TNBC by targeting CSC factor SOX8. MiR-200c also inhibits CSC-factor ZEB2 in TNBC, repressing $\mathrm{EMT}^{[223]}$. Altogether, these findings suggest that miRNAs that target known CSC regulators are likely to be negative regulators of TNBCSCs and could be investigated as biomarkers and therapeutics for TNBCSCs.

\section{CONCLUSION}

In this review, we provide an exhaustive summary of known regulatory mechanisms for CSCs in TNBC. We highlight transcriptional, epigenetic, and growth factor mechanisms that contribute to stemness with an emphasis on TNBC-specific mechanisms. It is worth noting that other mechanisms identified as contributors to CSC biology in other non-TNBC cancers, not highlighted here, would similarly play a role in TNBCSCs. These TNBC-specific mechanisms, however, are appealing therapeutic targets to combat relapse, recurrence, and therapy failure in this especially hard-to-treat cancer. Current approaches being pursued to combat CSCs in TNBC have recently been reviewed elsewhere ${ }^{[23,224]}$. Our scRNA-seq analysis also suggests there are several potential drivers of CSCs in TNBC yet to be described. Further work identifying and characterizing these CSC regulators is imperative. 


\section{DECLARATIONS}

\section{Authors' contributions}

Conceptualized and designed the review: Fultang N, Peethambaran B

Wrote the review and performed the scRNA-seq analysis: Fultang N

Reviewed the science and overall structure of the review: Chakrabory $\mathrm{M}$, Peethambaran $\mathrm{B}$

Reviewed the final manuscript: Fultang N, Chakrabory M, Peethambaran B

\section{Availability of data and materials}

The scRNA-seq data analyzed in this review is available at: https://www.ncbi.nlm.nih.gov/geo/query/acc. cgi?acc=GSE123366

All/R code used to analyze the data is available upon request.

\section{Financial support and sponsorship}

The research is supported by the Endowed Roth Funds for Natural Products awarded to Dr. Bela Peethambaran by The University of the Sciences, Philadelphia 19104.

\section{Conflicts of interest}

All authors declared that there are no conflicts of interest.

\section{Ethical approval and consent to participate}

Not applicable.

\section{Consent for publication}

Not applicable.

\section{Copyright}

(c) The Author(s) 2021.

\section{REFERENCES}

1. DeSantis CE, Ma J, Gaudet MM, et al. Breast cancer statistics, 2019. CA Cancer J Clin 2019;69:438-51.

2. Carey LA, Perou CM, Livasy CA, et al. Race, breast cancer subtypes, and survival in the Carolina Breast Cancer Study. JAMA 2006;295:2492-502.

3. Foulkes WD, Smith IE, Reis-Filho JS. Triple-negative breast cancer. $N$ Engl J Med 2010; 363:1938-48.

4. Burstein MD, Tsimelzon A, Poage GM, et al. Comprehensive genomic analysis identifies novel subtypes and targets of triple-negative breast cancer. Clin Cancer Res 2015;21:1688-98.

5. Boyle P. Triple-negative breast cancer: epidemiological considerations and recommendations. Ann Oncol 2012; 23 :vi7-12.

6. Griffiths CL, Olin JL. Triple negative breast cancer: a brief review of its characteristics and treatment options. $J$ Pharm Pract 2012;25:319-23.

7. Ballinger T, Kremer J, Miller K. Triple negative breast cancer-review of current and emerging therapeutic strategies. Oncology \& Hematology Review (US) 2016;12:89.

8. Ma F, Li H, Wang H, et al. Enriched CD44 $/$ CD24 population drives the aggressive phenotypes presented in triple-negative breast cancer (TNBC). Cancer Lett 2014;353:153-9.

9. $\quad$ Li H, Ma F, Wang H, et al. Stem cell marker aldehyde dehydrogenase 1 (ALDH1)-expressing cells are enriched in triple-negative breast cancer. Int J Biol Markers 2013;28:357-64.

10. Honeth G, Bendahl P-O, Ringnér M, et al. The CD44 $4^{+}$CD24 phenotype is enriched in basal-like breast tumors. Breast Cancer Res 2008;10:R53.

11. Talukdar S, Bhoopathi P, Emdad L, Das S, Sarkar D, Fisher PB. Dormancy and cancer stem cells: An enigma for cancer therapeutic targeting. Adv Cancer Res 2019;141:43-84.

12. Wicha MS, Liu S, Dontu G. Cancer stem cells: an old idea-a paradigm shift. Cancer Res 2006;66:1883-90

13. De Sousa e Melo F, Vermeulen L. Wnt signaling in cancer stem cell biology. Cancers 2016;8:60.

14. Braune E-B, Seshire A, Lendahl U. Notch and Wnt dysregulation and its relevance for breast cancer and tumor initiation. Biomedicines 2018;6:101.

15. Bhardwaj G, Murdoch B, Wu D, et al. Sonic hedgehog induces the proliferation of primitive human hematopoietic cells via BMP 
regulation. Nat Immunol 2001;2:172-80.

16. Aponte PM, Caicedo A. Stemness in cancer: stem cells, cancer stem cells, and their microenvironment. Stem Cells Int 2017;2017:5619472.

17. Serman L, Martic TN, Serman A, Vranic S. Epigenetic alterations of the Wnt signaling pathway in cancer: a mini review. Bosn J Basic Med Sci 2014;14:191.

18. Toh TB, Lim JJ, Chow EK-H. Epigenetics in cancer stem cells. Mol Cancer 2017;16:29.

19. Ricardo S, Vieira AF, Gerhard R, et al. Breast cancer stem cell markers CD44, CD24 and ALDH1: expression distribution within intrinsic molecular subtype. J Clin Pathol 2011;64:937-46.

20. Lee K-L, Kuo Y-C, Ho Y-S, Huang Y-H. Triple-negative breast cancer: Current understanding and future therapeutic breakthrough targeting cancer stemness. Cancers 2019;11:1334.

21. Liedtke C, Mazouni C, Hess KR, et al. Response to neoadjuvant therapy and long-term survival in patients with triple-negative breast cancer. J Clin Oncol Off J Am Soc Clin Oncol 2008;26:1275-81.

22. Petrelli F, Coinu A, Borgonovo K, et al. The value of platinum agents as neoadjuvant chemotherapy in triple-negative breast cancers: a systematic review and meta-analysis. Breast Cancer Res Treat 2014;144:223-32.

23. Park S-Y, Choi J-H, Nam J-S. Targeting Cancer Stem Cells in Triple-Negative Breast Cancer. Cancers 2019;11:965.

24. Qin J-J, Yan L, Zhang J, Zhang W-D. STAT3 as a potential therapeutic target in triple negative breast cancer: a systematic review. $J$ Exp Clin Cancer Res CR 2019;38:195.

25. Zhang F, Liu B, Deng Q, et al. UCP1 regulates ALDH-positive breast cancer stem cells through releasing the suppression of Snail on FBP1. Cell Biol Toxicol 2020.

26. Chaffer CL, Marjanovic ND, Lee T, et al. Poised chromatin at the ZEB1 promoter enables breast cancer cell plasticity and enhances tumorigenicity. Cell 2013;154:61-74.

27. Vesuna F, Lisok A, Kimble B, Raman V. Twist modulates breast cancer stem cells by transcriptional regulation of CD24 expression. Neoplasia N Y NY 2009;11:1318.

28. Zhang J-M, Wei K, Jiang M. OCT4 but not SOX2 expression correlates with worse prognosis in surgical patients with triple-negative breast cancer. Breast Cancer 2018;25:447-55.

29. Lee K, Giltnane JM, Balko JM, et al. MYC and MCL1 cooperatively promote chemotherapy-resistant breast cancer stem cells via regulation of mitochondrial oxidative phosphorylation. Cell Metab 2017;26:633-47.e7.

30. Samanta D, Gilkes DM, Chaturvedi P, Xiang L, Semenza GL. Hypoxia-inducible factors are required for chemotherapy resistance of breast cancer stem cells. Proc Natl Acad Sci 2014;111:E5429-38.

31. Fultang N, Peethambaran B. Wnt Signaling in Breast Cancer Oncogenesis, Development and Progression. In: Pandey MK, Kale VP, editors. Advances in Cancer Signal Transduction and Therapy. Bentham Science Publishes; 2020. p. 1-28.

32. Pohl S-G, Brook N, Agostino M, Arfuso F, Kumar AP, Dharmarajan A. Wnt signaling in triple-negative breast cancer. Oncogenesis 2017;6:e310.

33. Zhang S, Chen L, Cui B, et al. ROR1 is expressed in human breast cancer and associated with enhanced tumor-cell growth. PLoS One 2012;7:e31127.

34. Bilir B, Kucuk O, Moreno CS. Wnt signaling blockage inhibits cell proliferation and migration, and induces apoptosis in triple-negative breast cancer cells. $J$ Transl Med 2013;11:280.

35. Xu J, Prosperi JR, Choudhury N, Olopade OI, Goss KH. $\beta$-Catenin is required for the tumorigenic behavior of triple-negative breast cancer cells. PLoS One 2015;10:e117097.

36. Jang G-B, Kim J-Y, Cho S-D, et al. Blockade of Wnt/ $\beta$-catenin signaling suppresses breast cancer metastasis by inhibiting CSC-like phenotype. Sci Rep 2015;5:12465.

37. Giancotti FG. Mechanisms governing metastatic dormancy and reactivation. Cell 2013;155:750-64.

38. DiMeo TA, Anderson K, Phadke P, et al. A Novel Lung Metastasis Signature Links Wnt Signaling with Cancer Cell Self-Renewal and Epithelial-Mesenchymal Transition in Basal-like Breast Cancer. Cancer Res 2009;69:5364-73.

39. Debeb BG, Lacerda L, Xu W, et al. Histone Deacetylase Inhibitors Stimulate Dedifferentiation of Human Breast Cancer Cells Through WNT/B-Catenin Signaling. Stem Cells 2012;30:2366-77.

40. Lin C-C, Lo M-C, Moody R, et al. Targeting LRP8 inhibits breast cancer stem cells in triple-negative breast cancer. Cancer Lett 2018;438:165-73.

41. Henry C, Quadir A, Hawkins NJ, et al. Expression of the novel Wnt receptor ROR2 is increased in breast cancer and may regulate both $\beta$-catenin dependent and independent Wnt signalling. J Cancer Res Clin Oncol 2015;141:243-54.

42. Karvonen H, Barker H, Kaleva L, Niininen W, Ungureanu D. Molecular mechanisms associated with ROR1-mediated drug resistance: crosstalk with Hippo-YAP/TAZ and BMI-1 pathways. Cells 2019;8:812.

43. Chen J-F, Luo X, Xiang L-S, et al. EZH2 promotes colorectal cancer stem-like cell expansion by activating $\mathrm{p} 21$ cip1-Wnt/ $\beta$-catenin signaling. Oncotarget 2016;7:41540-58.

44. Zhang K, Guo Y, Wang X, et al. WNT/ $\beta$-catenin directs self-renewal symmetric cell division of hTERThigh prostate cancer stem cells. Cancer Res 2017;77:2534-47.

45. Ji C, Yang L, Yi W, et al. Capillary morphogenesis gene 2 maintains gastric cancer stem-like cell phenotype by activating a Wnt/ $\beta$-catenin pathway. Oncogene 2018;37:3953-66.

46. Wang T, Wu H, Liu S, et al. SMYD3 controls a Wnt-responsive epigenetic switch for ASCL2 activation and cancer stem cell maintenance. Cancer Lett 2018;430:11-24. 
47. Ibrahim SA, Hassan H, Vilardo L, et al. Syndecan-1 (CD138) modulates triple-negative breast cancer stem cell properties via regulation of LRP-6 and IL-6-mediated STAT3 signaling. PLoS One 2013;8:e85737.

48. Kolev VN, Tam WF, Wright QG, et al. Inhibition of FAK kinase activity preferentially targets cancer stem cells. Oncotarget 2017;8:51733-47.

49. Cleary AS, Leonard TL, Gestl SA, Gunther EJ. Tumour cell heterogeneity maintained by cooperating subclones in Wnt-driven mammary cancers. Nature 2014;508:113-7.

50. Schroeter EH, Kisslinger JA, Kopan R. Notch-1 signalling requires ligand-induced proteolytic release of intracellular domain. Nature 1998;393:382-6.

51. Kovall RA. More complicated than it looks: assembly of Notch pathway transcription complexes. Oncogene 2008;27:5099-109.

52. Giuli MV, Giuliani E, Screpanti I, Bellavia D, Checquolo S. Notch signaling activation as a hallmark for triple-negative breast cancer subtype. J Oncol 2019;2019:8707053.

53. Stylianou S, Clarke RB, Brennan K. Aberrant activation of notch signaling in human breast cancer. Cancer Res 2006;66:1517-25.

54. Harrison H, Farnie G, Howell SJ, et al. Regulation of breast cancer stem cell activity by signaling through the Notch4 receptor. Cancer Res 2010;70:709-18.

55. Speiser J, Foreman K, Drinka E, et al. Notch-1 and Notch-4 biomarker expression in triple-negative breast cancer. Int J Surg Pathol 2012;20:139-45.

56. Yu F, Li J, Chen H, et al. Kruppel-like factor 4 (KLF4) is required for maintenance of breast cancer stem cells and for cell migration and invasion. Oncogene 2011;30:2161-72.

57. Choi S, Yu J, Park A, et al. BMP-4 enhances epithelial mesenchymal transition and cancer stem cell properties of breast cancer cells via Notch signaling. Sci Rep 2019;9:11724.

58. Bernardi R, Gianni L. Hallmarks of triple negative breast cancer emerging at last? Cell Res 2014;24:904-5.

59. Xing F, Okuda $\mathrm{H}$, Watabe M, et al. Hypoxia-induced Jagged2 promotes breast cancer metastasis and self-renewal of cancer stem-like cells. Oncogene 2011;30:4075-86.

60. Zhang J, Shao X, Sun H, et al. NUMB negatively regulates the epithelial-mesenchymal transition of triple-negative breast cancer by antagonizing Notch signaling. Oncotarget 2016;7:61036-53.

61. Takada M, Zhuang M, Inuzuka H, et al. EglN2 contributes to triple negative breast tumorigenesis by functioning as a substrate for the FBW7 tumor suppressor. Oncotarget 2017;8:6787-95.

62. Meyer AE, Furumo Q, Stelloh C, Minella AC, Rao S. Loss of Fbxw7 triggers mammary tumorigenesis associated with E2F/c-Myc activation and Trp53 mutation. Neoplasia 2020;22:644-58.

63. Liubomirski Y, Lerrer S, Meshel T, et al. Notch-mediated tumor-stroma-inflammation networks promote invasive properties and CXCL8 expression in triple-negative breast cancer. Front Immunol 2019;10:804.

64. Merchant AA, Matsui W. Targeting Hedgehog-a cancer stem cell pathway. Clin Cancer Res 2010;16:3130-40.

65. Skoda AM, Simovic D, Karin V, Kardum V, Vranic S, Serman L. The role of the Hedgehog signaling pathway in cancer: A comprehensive review. Bosn J Basic Med Sci 2018;18:8-20.

66. Habib JG, O'Shaughnessy JA. The hedgehog pathway in triple-negative breast cancer. Cancer Med 2016;5:2989-3006.

67. O'Toole SA, Machalek DA, Shearer RF, et al. Hedgehog overexpression is associated with stromal interactions and predicts for poor outcome in breast cancer. Cancer Res 2011;71:4002-14.

68. Han B, Qu Y, Jin Y, et al. FOXC1 activates smoothened-independent hedgehog signaling in basal-like breast cancer. Cell Rep 2015;13:1046-58.

69. Tao Y, Mao J, Zhang Q, Li L. Overexpression of Hedgehog signaling molecules and its involvement in triple-negative breast cancer. Oncol Lett 2011;2:995-1001

70. Chen B, Dodge ME, Tang W, et al. Small molecule-mediated disruption of Wnt-dependent signaling in tissue regeneration and cancer. Nat Chem Biol 2009;5:100-7.

71. Reyes-Ramos AM, Ramos-Cruz KP, Rodríguez-Merced NJ, et al. Mesenchymal Cells Support the Oncogenicity and Therapeutic Response of the Hedgehog Pathway in Triple-Negative Breast Cancer. Cancers 2019;11:1522.

72. Guerrini G, Durivault J, Filippi I, et al. Carbonic anhydrase XII expression is linked to suppression of Sonic hedgehog ligand expression in triple negative breast cancer cells. Biochem Biophys Res Commun 2019;516:408-13.

73. Nagata T, Shimada Y, Sekine S, et al. KLF4 and NANOG are prognostic biomarkers for triple-negative breast cancer. Breast Cancer 2017;24:326-35.

74. Li Q, Lex RK, Chung H, et al. The pluripotency factor NANOG binds to GLI proteins and represses hedgehog-mediated transcription. $J$ Biol Chem 2016;291:7171-82.

75. Durand N, Borges S, Storz P. Protein Kinase D Enzymes as Regulators of EMT and Cancer Cell Invasion. J Clin Med 2016;5:20.

76. Durand N, Borges S, Storz P. Functional and therapeutic significance of protein kinase D enzymes in invasive breast cancer. Cell Mol Life Sci 2015;72:4369-82.

77. Alpsoy A, Gündüz U. Protein kinase D2 silencing reduced motility of doxorubicin-resistant MCF7 cells. Tumor Biol 2015;36:4417-26.

78. Borges S, Döppler H, Perez EA, et al. Pharmacologic reversion of epigenetic silencing of the PRKD1 promoter blocks breast tumor cell invasion and metastasis. Breast Cancer Res 2013;15:R66.

79. Hao Q, Mckenzie R, Gan H, Tang H. Protein Kinases D2 and D3 Are Novel Growth Regulators in HCC1806 Triple-negative Breast Cancer Cells. Anticancer Res 2013;33:393-99.

80. Lieb WS, Lungu C, Tamas R, et al. The GEF-H1/PKD3 signaling pathway promotes the maintenance of triple-negative breast cancer 
stem cells. Int J Cancer 2020;146:3423-34.

81. Huck B, Duss S, Hausser A, Olayioye MA. Elevated protein kinase D3 (PKD3) expression supports proliferation of triple-negative breast cancer cells and contributes to mTORC1-S6K1 pathway activation. J Biol Chem 2014;289:3138-47.

82. Huck B, Kemkemer R, Franz-Wachtel M, Macek B, Hausser A, Olayioye MA. GIT1 phosphorylation on serine 46 by PKD3 regulates paxillin trafficking and cellular protrusive activity. $J$ Biol Chem 2012;287:34604-13.

83. Harrison DA. The Jak/STAT pathway. Cold Spring Harb Perspect Biol 2012;4:a011205.

84. Ghoreschi K, Laurence A, O'Shea JJ. Janus kinases in immune cell signaling. Immunol Rev 2009;228:273-87.

85. Tang Y, Tian X (Cindy). JAK-STAT3 and somatic cell reprogramming. JAKSTAT 2013;2:e24935.

86. Boudny V, Kovarik J. JAK/STAT signaling pathways and cancer. Janus kinases/signal transducers and activators of transcription. Neoplasma 2002;49:349-55.

87. Kim S-Y, Kang JW, Song X, et al. Role of the IL-6-JAK1-STAT3-Oct-4 pathway in the conversion of non-stem cancer cells into cancer stem-like cells. Cell Signal 2013;25:961-9.

88. Marotta LL, Almendro V, Marusyk A, et al. The JAK2/STAT3 signaling pathway is required for growth of CD44 $4^{+} \mathrm{CD} 24^{-}$stem cell-like breast cancer cells in human tumors. $J$ Clin Invest 2011;121:2723-35.

89. Ginestier C, Liu S, Diebel ME, et al. CXCR1 blockade selectively targets human breast cancer stem cells in vitro and in xenografts. $J$ Clin Invest 2010;120:485-97.

90. Hartman ZC, Poage GM, Den Hollander P, et al. Growth of triple-negative breast cancer cells relies upon coordinate autocrine expression of the proinflammatory cytokines IL-6 and IL-8. Cancer Res 2013;73:3470-80.

91. Thiagarajan PS, Zheng Q, Bhagrath M, et al. STAT3 activation by leptin receptor is essential for TNBC stem cell maintenance. Endocr Relat Cancer 2017;24:415-26.

92. Liu Y, Choi DS, Sheng J, et al. HN1L promotes triple-negative breast cancer stem cells through LEPR-STAT3 pathway. Stem Cell Rep 2018;10:212-27.

93. Barbie TU, Alexe G, Aref AR, et al. Targeting an IKBKE cytokine network impairs triple-negative breast cancer growth. $J$ Clin Invest 2014;124:5411-23.

94. Doherty MR, Cheon H, Junk DJ, et al. Interferon-beta represses cancer stem cell properties in triple-negative breast cancer. Proc Natl Acad Sci 2017;114:13792-7.

95. Qadir AS, Ceppi P, Brockway S, et al. CD95/Fas increases stemness in cancer cells by inducing a STAT1-dependent type I interferon response. Cell Rep 2017;18:2373-86.

96. Verrecchia F, Mauviel A. TGF-beta and TNF-alpha: antagonistic cytokines controlling type I collagen gene expression. Cell Signal 2004; $16: 873-80$

97. Dash S, Sahu AK, Srivastava A, Chowdhury R, Mukherjee S. Exploring the extensive crosstalk between the antagonistic cytokinesTGF- $\beta$ and TNF- $\alpha$ in regulating cancer pathogenesis. Cytokine 2020;155348.

98. Moses H, Barcellos-Hoff MH. TGF- $\beta$ biology in mammary development and breast cancer. Cold Spring Harb Perspect Biol 2011;3:a003277.

99. Zarzynska JM. Two faces of TGF-beta1 in breast cancer. Mediators Inflamm 2014;2014:141747.

100. Lamouille S, Xu J, Derynck R. Molecular mechanisms of epithelial-mesenchymal transition. Nat Rev Mol Cell Biol 2014;15:178-96.

101. Moustakas A, Heldin C-H. Induction of epithelial-mesenchymal transition by transforming growth factor $\beta$. Seminars in cancer biology 2012;22:446-54.

102. Derynck R, Muthusamy BP, Saeteurn KY. Signaling pathway cooperation in TGF- $\beta$-induced epithelial-mesenchymal transition. Curr Opin Cell Biol 2014;31:56-66.

103. Gonzalez DM, Medici D. Signaling mechanisms of the epithelial-mesenchymal transition. Sci Signal 2014;7:re8.

104. Shipitsin M, Campbell LL, Argani P, et al. Molecular definition of breast tumor heterogeneity. Cancer Cell 2007;11:259-73.

105. Bhola NE, Balko JM, Dugger TC, et al. TGF- $\beta$ inhibition enhances chemotherapy action against triple-negative breast cancer. $J$ Clin Invest 2013;123:1348-58.

106. Serra R, Easter SL, Jiang W, Baxley SE. Wnt5a as an effector of TGF $\beta$ in mammary development and cancer. J Mammary Gland Biol Neoplasia 2011;16:157-67.

107. Bierie B, Stover DG, Abel TW, et al. Transforming growth factor- $\beta$ regulates mammary carcinoma cell survival and interaction with the adjacent microenvironment. Cancer Res 2008;68:1809-19.

108. Lindau D, Gielen P, Kroesen M, Wesseling P, Adema GJ. The immunosuppressive tumour network: myeloid-derived suppressor cells, regulatory T cells and natural killer T cells. Immunology 2013;138:105-15.

109. Cabrera MC, Hollingsworth RE, Hurt EM. Cancer stem cell plasticity and tumor hierarchy. World J Stem Cells 2015;7:27-36.

110. Balkwill F. Tumour necrosis factor and cancer. Nat Rev Cancer 2009;9:361-71.

111. Liu W, Lu X, Shi P, et al. TNF- $\alpha$ increases breast cancer stem-like cells through up-regulating tAZ expression via the non-canonical nfкB pathway. Sci Rep 2020;10:1804.

112. Storci G, Sansone P, Mari S, et al. TNFalpha up-regulates SLUG via the NF-kappaB/HIF1alpha axis, which imparts breast cancer cells with a stem cell-like phenotype. J Cell Physiol 2010;225:682-91.

113. Li C-W, Xia W, Huo L, et al. Epithelial-mesenchymal transition induced by TNF- $\alpha$ requires NF-אB-mediated transcriptional upregulation of Twist1. Cancer Res 2012;72:1290-300.

114. Fresno JV, Casado E, Cejas P, Belda-Iniesta C, González-Barón M. PI3K/Akt signalling pathway and cancer. Cancer Treat Rev 2004;30:193-204. 
115. Bai J, Chen W-B, Zhang X-Y, et al. HIF-2 $\alpha$ regulates CD44 to promote cancer stem cell activation in triple-negative breast cancer via $\mathrm{PI} 3 \mathrm{~K} / \mathrm{AKT} / \mathrm{mTOR}$ signaling. World J Stem Cells 2020;12:87-99.

116. Rivas S, Gómez-Oro C, Antón IM, Wandosell F. Role of Akt Isoforms Controlling Cancer Stem Cell Survival, Phenotype and SelfRenewal. Biomedicines 2018;6:29.

117. Abraham AG, O’Neill E. PI3K/Akt-mediated regulation of p53 in cancer. Biochem Soc Trans 2014;42:798-803.

118. Pascual J, Turner NC. Targeting the PI3-kinase pathway in triple-negative breast cancer. Ann Oncol Off J Eur Soc Med Oncol 2019;30:1051-60.

119. Martínez-Revollar G, Garay E, Martin-Tapia D, et al. Heterogeneity between triple negative breast cancer cells due to differential activation of Wnt and PI3K/AKT pathways. Exp Cell Res 2015;339:67-80.

120. Sulaiman A, McGarry S, Lam KM, et al. Co-inhibition of mTORC1, HDAC and ESR1 $\alpha$ retards the growth of triple-negative breast cancer and suppresses cancer stem cells. Cell Death Dis 2018;9:815.

121. Tian J, Al Raffa F, Dai M, et al. Dasatinib sensitises triple negative breast cancer cells to chemotherapy by targeting breast cancer stem cells. Br J Cancer 2018;119:1495-507.

122. Britschgi A, Andraos R, Brinkhaus H, et al. JAK2/STAT5 inhibition circumvents resistance to PI3K/mTOR blockade: a rationale for cotargeting these pathways in metastatic breast cancer. Cancer Cell 2012;22:796-811.

123. Brabletz T, Kalluri R, Nieto MA, Weinberg RA. EMT in cancer. Nat Rev Cancer 2018;18:128-34.

124. Jiralerspong S, Liu S, Palla SL, Mills GB, Hung M, Horyobagyi GN, Gonzalez-Angulo M. Correlation of Snail expression and survival in patients with early-stage triple-negative breast cancer (TNBC). J Clin Oncol 2010;28:10525.

125. Hwang W-L, Yang M-H, Tsai M-L, et al. SNAIL regulates interleukin-8 expression, stem cell-like activity, and tumorigenicity of human colorectal carcinoma cells. Gastroenterology 2011;141:279-91, 291.e1-5.

126. Dong C, Yuan T, Wu Y, et al. Loss of FBP1 by Snail-mediated repression provides metabolic advantages in basal-like breast cancer. Cancer Cell 2013;23:316-31.

127. Lu L, Chen Z, Lin X, et al. Inhibition of BRD4 suppresses the malignancy of breast cancer cells via regulation of Snail. Cell Death Differ 2020;27:255-68.

128. Feldker N, Ferrazzi F, Schuhwerk H, et al. Genome-wide cooperation of EMT transcription factor ZEB 1 with YAP and AP-1 in breast cancer. EMBO J 2020;39:e103209.

129. He Y, Zhang X, Pan W, Tai F, Liang L, Shi J. Interleukin-31 Receptor $\alpha$ Is Required for Basal-Like Breast Cancer Progression. Front Oncol 2020;10:816.

130. Shi J, Wang Y, Zeng L, et al. Disrupting the interaction of BRD4 with diacetylated Twist suppresses tumorigenesis in basal-like breast cancer. Cancer Cell 2014;25:210-25.

131. He J, Lee H-J, Saha S, Ruan D, Guo H, Chan CH. Inhibition of USP2 eliminates cancer stem cells and enhances TNBC responsiveness to chemotherapy. Cell Death Dis 2019;10:285.

132. Bao B, Azmi AS, Ali S, et al. The biological kinship of hypoxia with CSC and EMT and their relationship with deregulated expression of miRNAs and tumor aggressiveness. Biochim Biophys Acta 2012;1826:272-96.

133. Lu H, Samanta D, Xiang L, et al. Chemotherapy triggers HIF-1-dependent glutathione synthesis and copper chelation that induces the breast cancer stem cell phenotype. Proc Natl Acad Sci 2015;112:E4600-9.

134. Chaturvedi P, Gilkes DM, Takano N, Semenza GL. Hypoxia-inducible factor-dependent signaling between triple-negative breast cancer cells and mesenchymal stem cells promotes macrophage recruitment. Proc Natl Acad Sci 2014;111:E2120-9.

135. Zhang H, Lu H, Xiang L, et al. HIF-1 regulates CD47 expression in breast cancer cells to promote evasion of phagocytosis and maintenance of cancer stem cells. Proc Natl Acad Sci 2015;112:E6215-23.

136. Lan J, Lu H, Samanta D, Salman S, Lu Y, Semenza GL. Hypoxia-inducible factor 1-dependent expression of adenosine receptor 2B promotes breast cancer stem cell enrichment. Proc Natl Acad Sci 2018;115:E9640-8.

137. Xiang L, Gilkes DM, Hu H, et al. Hypoxia-inducible factor 1 mediates TAZ expression and nuclear localization to induce the breast cancer stem cell phenotype. Oncotarget 2014;5:12509-27.

138. Zandberga E, Zayakin P, Ābols A, Pūpola D, Trapencieris P, Linē A. Depletion of carbonic anhydrase IX abrogates hypoxia-induced overexpression of stanniocalcin-1 in triple negative breast cancer cells. Cancer Biol Ther 2017;18:596-605.

139. Lock FE, McDonald PC, Lou Y, et al. Targeting carbonic anhydrase IX depletes breast cancer stem cells within the hypoxic niche. Oncogene 2013;32:5210-9.

140. Sarnella A, D'Avino G, Hill BS, et al. A Novel Inhibitor of Carbonic Anhydrases Prevents Hypoxia-Induced TNBC Cell Plasticity. Int $J$ Mol Sci 2020;21:8405.

141. Liu A, Yu X, Liu S. Pluripotency transcription factors and cancer stem cells: small genes make a big difference. Chin J Cancer 2013;32:483-7.

142. Li Y, Zhao H, Lan F, et al. Generation of human-induced pluripotent stem cells from gut mesentery-derived cells by ectopic expression of OCT4/SOX2/NANOG. Cell Reprogramming 2010;12:237-47.

143. Nichols J, Zevnik B, Anastassiadis K, et al. Formation of pluripotent stem cells in the mammalian embryo depends on the POU transcription factor Oct4. Cell 1998;95:379-91.

144. Wang Y-J, Herlyn M. The emerging roles of Oct4 in tumor-initiating cells. Am J Physiol-Cell Physiol 2015;309:C709-18.

145. Cheng C-C, Shi L-H, Wang X-J, et al. Stat3/Oct-4/c-Myc signal circuit for regulating stemness-mediated doxorubicin resistance of triplenegative breast cancer cells and inhibitory effects of WP1066. Int J Oncol 2018;53:339-48.

146. Jin X, Liu Y, Qu H, Qi D, Wang X, et al. OCT4 Suppresses Metastasis in Breast Cancer Cells Through Activation of STAT3 Signaling. 
Research Square 2020.

147. Yao GD, Niu YY, Chen KX, et al. SOX2 gene expression and its role in triple negative breast cancer tissues. J Biol Regul Homeost Agents 2018;32:1399-406.

148. Liu P, Tang H, Song C, et al. SOX2 promotes cell proliferation and metastasis in triple negative breast cancer. Front Pharmacol 2018;9:942.

149. Mukherjee P, Gupta A, Chattopadhyay D, Chatterji U. Modulation of SOX2 expression delineates an end-point for paclitaxeleffectiveness in breast cancer stem cells. Sci Rep 2017;7:1-16.

150. Jung K, Gupta N, Wang P, et al. Triple negative breast cancers comprise a highly tumorigenic cell subpopulation detectable by its high responsiveness to a sex determining region Y box 2 (Sox2) regulatory region 2 (SRR2) reporter. Oncotarget 2015;6:10366.

151. Samanta S, Sun H, Goel HL, et al. IMP3 promotes stem-like properties in triple-negative breast cancer by regulating SLUG. Oncogene 2016;35:1111-21.

152. Zhao D, Pan C, Sun J, et al. VEGF drives cancer-initiating stem cells through VEGFR-2/Stat3 signaling to upregulate Myc and Sox2. Oncogene 2015;34:3107-19.

153. Zhang Y, Zhu X, Qiao X, et al. LIPH promotes metastasis by enriching stem-like cells in triple-negative breast cancer. $J$ Cell Mol Med 2020;24:9125-34.

154. Schwarz BA, Bar-Nur O, Silva JC, Hochedlinger K. Nanog is Dispensable for the Generation of Induced Pluripotent Stem Cells. Curr Biol CB 2014;24:347-50.

155. Thiagarajan PS, Sinyuk M, Turaga SM, et al. Cx26 drives self-renewal in triple-negative breast cancer via interaction with NANOG and focal adhesion kinase. Nat Commun 2018;9:1-14.

156. Nagata T, Shimada Y, Sekine S, et al. Prognostic significance of NANOG and KLF4 for breast cancer. Breast Cancer 2014;21:96-101.

157. Qi X, Yin N, Ma S, et al. p38 MAPK is a therapeutic target for triple-negative breast cancer by stimulation of cancer stem-like cell expansion. Stem Cells 2015 33:2738-47.

158. Rowland BD, Bernards R, Peeper DS. The KLF4 tumour suppressor is a transcriptional repressor of $\mathrm{p} 53$ that acts as a context-dependent oncogene. Nat Cell Biol 2005;7:1074-82.

159. Nagata T, Shimada K, Long XL, et al. KLF4 Improve Prognosis of Triple-negative Breast Cancer by Suppression of Epithelialmesenchymal Transition. Breast Can Curr Res 2016;01.

160. Zhou Z, Feng Z, Hu D, et al. A novel small-molecule antagonizes PRMT5-mediated KLF4 methylation for targeted therapy. EBioMedicine 2019;44:98-111.

161. Sharma SB. Kruppel-like factor 4 (KLF4) regulates protumorigenic signaling in triple-negative breast cancer (TNBC) cells. Graduate Theses, Dissertations, and Problem Reports 2015.

162. Dang CV. MYC on the Path to Cancer. Cell 2012;149:22-35.

163. Yang A, Qin S, Schulte BA, Ethier SP, Tew KD, Wang GY. MYC inhibition depletes cancer stem-like cells in triple-negative breast cancer. Cancer Res 2017;77:6641-50.

164. Yin S, Cheryan VT, Xu L, Rishi AK, Reddy KB. Myc mediates cancer stem-like cells and EMT changes in triple negative breast cancers cells. PLoS One 2017;12:e183578.

165. Lee Y-C, Chang W-W, Chen Y-Y, et al. Hsp90 $\alpha$ mediates BMI1 expression in breast cancer stem/progenitor cells through facilitating nuclear translocation of c-Myc and EZH2. Int J Mol Sci 2017;18:1986.

166. Teo WS, Holliday H, Karthikeyan N, et al. Id proteins promote a cancer stem cell phenotype in triple negative breast cancer via Robo1dependent c-Myc activation. bioRxiv 2019:497313.

167. Ito Y, Bae S-C, Chuang LSH. The RUNX family: developmental regulators in cancer. Nat Rev Cancer 2015;15:81-95.

168. Ferrari N. Investigating RUNX transcription factors in mammary gland development and breast cancer. 2013.

169. Fritz AJ, Hong D, Boyd J, et al. RUNX transcription factor mediated control of breast cancer stem cells. J Cell Physiol 2020;235:726172.

170. Ferrari N, Mohammed ZM, Nixon C, et al. Expression of RUNX1 correlates with poor patient prognosis in triple negative breast cancer. PLoS One 2014;9:e100759.

171. Ran R, Harrison H, Ariffin NS, et al. RUNX/CBF $\beta$ transcription factor complexes promote the phenotypic plasticity of metastatic breast cancer cells. bioRxiv 2019:562538.

172. Felcher CM, Tocci JM, Sola MEG, Bushweller JH, Kordon EC. Inhibition of RUNX-CBF $\beta$ binding reduces RSPO3 expression and EMT features in breast cancer cells. AACR Annual Meeting 2020; Philadelphia, PA.

173. Passaniti A, Brusgard JL, Qiao Y, Sudol M, Finch-Edmondson M. Roles of RUNX in Hippo pathway signaling. In: Groner Y, Ito Y, Liu P, Neil JC, Speck NA, van Wijnen A, editors. RUNX Proteins in Development and Cancer. Singapore: Springer; 2017. pp. 435-48.

174. Piccolo S, Dupont S, Cordenonsi M. The biology of YAP/TAZ: hippo signaling and beyond. Physiol Rev 2014;94:1287-312.

175. Yimlamai D, Christodoulou C, Galli GG, et al. Hippo pathway activity influences liver cell fate. Cell 2014;157:1324-38.

176. Cordenonsi M, Zanconato F, Azzolin L, et al. The Hippo transducer TAZ confers cancer stem cell-related traits on breast cancer cells. Cell 2011;147:759-72.

177. Kim T, Yang S-J, Hwang D, et al. A basal-like breast cancer-specific role for SRF-IL6 in YAP-induced cancer stemness. Nat Commun 2015;6:10186.

178. Guo L, Zheng J, Zhang J, Wang H, Shao G, Teng L. Knockdown of TAZ modifies triple-negative breast cancer cell sensitivity to EGFR inhibitors by regulating YAP expression. Oncol Rep 2016;36:729-36.

179. Sorrentino G, Ruggeri N, Zannini A, et al. Glucocorticoid receptor signalling activates YAP in breast cancer. Nat Commun 2017;8:14073. 
180. Knight JF, Sung VY, Kuzmin E, et al. KIBRA (WWC1) Is a metastasis suppressor gene affected by chromosome 5q loss in triple-negative breast cancer. Cell Rep 2018;22:3191-205.

181. Mussell A, Shen H, Chen Y, et al. USP1 Regulates TAZ Protein Stability Through Ubiquitin Modifications in Breast Cancer. Cancers 2020;12:3090.

182. Taniguchi K, Karin M. NF-אB, inflammation, immunity and cancer: coming of age. Nat Rev Immunol 2018;18:309-24.

183. Yamamoto M, Taguchi Y, Ito-Kureha T, Semba K, Yamaguchi N, Inoue J. NF-кB non-cell-autonomously regulates cancer stem cell populations in the basal-like breast cancer subtype. Nat Commun 2013;4:2299.

184. Hossain F, Sorrentino C, Ucar DA, et al. Notch signaling regulates mitochondrial metabolism and NF- $\kappa B$ activity in triple-negative breast cancer cells via IKK $\alpha$-dependent non-canonical pathways. Front Oncol 2018;8:575.

185. Orlova Z, Pruefer F, Castro-Oropeza R, et al. IKK\& regulates the breast cancer stem cell phenotype. Biochim Biophys Acta BBA-Mol Cell Res 2019;1866:598-611.

186. Patel AP, Tirosh I, Trombetta JJ, et al. Single-cell RNA-seq highlights intratumoral heterogeneity in primary glioblastoma. Science 2014;344:1396-401.

187. Horning AM, Wang Y, Lin C-K, et al. Single-Cell RNA-seq reveals a subpopulation of prostate cancer cells with enhanced cell-CycleRelated transcription and attenuated androgen response. Cancer Res 2018;78:853-64.

188. Zhao Y, Carter R, Natarajan S, et al. Single-cell RNA sequencing reveals the impact of chromosomal instability on glioblastoma cancer stem cells. BMC Med Genomics 2019;12:79.

189. Yeo SK, Zhu X, Okamoto T, et al. Single-cell RNA-sequencing reveals distinct patterns of cell state heterogeneity in mouse models of breast cancer. Elife 2020;9:e58810.

190. Butler A, Hoffman P, Smibert P, Papalexi E, Satija R. Integrating single-cell transcriptomic data across different conditions, technologies, and species. Nat Biotechnol 2018;36:411-20.

191. Ren D, Zhu X, Kong R, et al. Targeting brain-adaptive cancer stem cells prohibits brain metastatic colonization of triple-negative breast cancer. Cancer Res 2018;78:2052-64.

192. da Silveira WA, Palma PVB, Sicchieri RD, et al. Transcription Factor Networks derived from Breast Cancer Stem Cells control the immune response in the Basal subtype. Sci Rep 2017;7:2851.

193. Chen K-HE, Chen C, Lopez T, et al. Use of a novel camelid-inspired human antibody demonstrates the importance of MMP-14 to cancer stem cell function in the metastatic process. Oncotarget 2018;9:29431-44.

194. Kulesza DW, Przanowski P, Kaminska B. Knockdown of STAT3 targets a subpopulation of invasive melanoma stem-like cells. Cell Biol Int 2019;43:613-22.

195. Oktem G, Sercan O, Guven U, et al. Cancer stem cell differentiation: TGF $\beta 1$ and versican may trigger molecules for the organization of tumor spheroids. Oncol Rep 2014;32:641-9.

196. Chen Z, Liu Y, Yao L, Guo S, Gao Y, Zhu P. The long noncoding RNA lncZic2 drives the self-renewal of liver tumor-initiating cells via the protein kinase C substrates MARCKS and MARCKSL1. J Biol Chem 2018;293:7982-92.

197. Man J, Yu X, Huang H, et al. Hypoxic induction of vasorin regulates Notch1 turnover to maintain glioma stem-like cells. Cell Stem Cell 2018;22:104-18.e6.

198. Huang D, Casale GP, Tian J, et al. Udp-glucose dehydrogenase as a novel field-specific candidate biomarker of prostate cancer. Int $J$ Cancer 2010;126:315-27.

199. Temian DC, Pop LA, Irimie AI, Berindan-Neagoe I. The Epigenetics of Triple-Negative and Basal-Like Breast Cancer: Current Knowledge. J Breast Cancer 2018;21:233-43.

200. Li G, Wang D, Ma W, et al. Transcriptomic and epigenetic analysis of breast cancer stem cells. Epigenomics 2018;10:765-83.

201. Kagara N, Huynh KT, Kuo C, et al. Epigenetic regulation of cancer stem cell genes in triple-negative breast cancer. Am J Pathol 2012;181:257-67.

202. Schech A, Kazi A, Yu S, Shah P, Sabnis G. Histone deacetylase inhibitor entinostat inhibits tumor-initiating cells in triple-negative breast cancer cells. Mol Cancer Ther 2015;14:1848-57.

203. Stirzaker C, Zotenko E, Song JZ, et al. Methylome sequencing in triple-negative breast cancer reveals distinct methylation clusters with prognostic value. Nat Commun 2015;6:5899.

204. Nakai K, Xia W, Liao H-W, Saito M, Hung M-C, Yamaguchi H. The role of PRMT1 in EGFR methylation and signaling in MDAMB-468 triple-negative breast cancer cells. Breast Cancer 2018;25:74-80.

205. Xiong Z, Yang L, Yang L, et al. Decitabine Reverses CSC-Induced Docetaxel Resistance via Epigenetic Regulation of DAB2IP in TNBC. Research Saquare 2020.

206. Bao B, Teslow EA, Mitrea C, Boerner JL, Dyson G, Bollig-Fischer A. Role of TET1 and 5hmC in an Obesity-Linked Pathway Driving Cancer Stem Cells in Triple-Negative Breast Cancer. Mol Cancer Res 2020;18:1803-14.

207. Jones PA, Baylin SB. The epigenomics of cancer. Cell 2007;128:683-92.

208. Yomtoubian S, Lee SB, Verma A, et al. Inhibition of EZH2 Catalytic Activity Selectively Targets a Metastatic Subpopulation in TripleNegative Breast Cancer. Cell Rep 2020;30:755-70.e6.

209. Witt AE, Lee C-W, Lee TI, et al. Identification of a cancer stem cell-specific function for the histone deacetylases, HDAC1 and HDAC7, in breast and ovarian cancer. Oncogene 2017;36:1707-20.

210. Caslini C, Hong S, Ban YJ, Chen XS, Ince TA. HDAC7 regulates histone 3 lysine 27 acetylation and transcriptional activity at superenhancer-associated genes in breast cancer stem cells. Oncogene 2019;38:6599-614.

211. Su Y, Hopfinger NR, Nguyen TD, Pogash TJ, Santucci-Pereira J, Russo J. Epigenetic reprogramming of epithelial mesenchymal transition 
in triple negative breast cancer cells with DNA methyltransferase and histone deacetylase inhibitors. J Exp Clin Cancer Res 2018;37:314.

212. Darvin P, Sasidharan Nair V, Elkord E. PD-L1 Expression in Human Breast Cancer Stem Cells Is Epigenetically Regulated through Posttranslational Histone Modifications. J Oncol 2019;2019:e3958908.

213. Torres CM, Biran A, Burney MJ, et al. The linker histone H1.0 generates epigenetic and functional intratumor heterogeneity. Science 2016;353:aaf1644.

214. Li X, Strietz J, Bleilevens A, Stickeler E, Maurer J. Chemotherapeutic Stress Influences Epithelial-Mesenchymal Transition and Stemness in Cancer Stem Cells of Triple-Negative Breast Cancer. Int J Mol Sci 2020;21:404.

215. Huang QD, Zheng SR, Cai YJ, et al. IMP3 promotes TNBC stem cell property through miRNA-34a regulation. Eur Rev Med Pharmacol Sci 2018;22:2688-96.

216. Sun X, Li Y, Zheng M, Zuo W, Zheng W. MicroRNA-223 Increases the Sensitivity of Triple-Negative Breast Cancer Stem Cells to TRAIL-Induced Apoptosis by Targeting HAX-1. PLoS One 2016;11:e0162754.

217. DeCastro AJ, Dunphy KA, Hutchinson J, Balboni AL, Cherukuri P, Jerry DJ, DiRenzo J. MiR203 mediates subversion of stem cell properties during mammary epithelial differentiation via repression of $\triangle \mathrm{NP} 63 \alpha$ and promotes mesenchymal-to-epithelial transition. Cell Death Dis 2013;4:e514.

218. Taube JH, Malouf GG, Lu E, et al. Epigenetic silencing of microRNA-203 is required for EMT and cancer stem cell properties. Sci Rep 2013;3:2687.

219. Wellner U, Schubert J, Burk UC, et al. The EMT-activator ZEB1 promotes tumorigenicity by repressing stemness-inhibiting microRNAs. Nat Cell Biol 2009;11:1487-95.

220. Sempere LF, Christensen M, Silahtaroglu A, et al. Altered MicroRNA expression confined to specific epithelial cell subpopulations in breast cancer. Cancer Res 2007;67:11612-20.

221. Chao C-H, Chang C-C, Wu M-J, et al. MicroRNA-205 signaling regulates mammary stem cell fate and tumorigenesis. $J$ Clin Invest 2014;124:3093-106.

222. Dong L, Zhou D, Xin C, Liu B, Sun P. MicroRNA-139 Suppresses the Tumorigenicity of Triple Negative Breast Cancer Cells by Targeting SOX8. Cancer Manag Res 2020;12:9417-28.

223. Chen H, Li Z, Zhang L, et al. MicroRNA-200c Inhibits the Metastasis of Triple-Negative Breast Cancer by Targeting ZEB2, an EpithelialMesenchymal Transition Regulator. Ann Clin Lab Sci 2020;50:519-27.

224. Sulaiman A, McGarry S, Han X, Liu S, Wang L. CSCs in Breast Cancer-One Size Does Not Fit All: Therapeutic Advances in Targeting Heterogeneous Epithelial and Mesenchymal CSCs. Cancers 2019;11:1128. 